\title{
Basal forebrain amnesia: does the nucleus accumbens contribute to human memory?
}

\author{
Georg Goldenberg, Uwe Schuri, Olaf Grömminger, Ursula Arnold
}

\begin{abstract}
Objective-To analyse amnesia caused by basal forebrain lesions.

Methods-A single case study of a patient with amnesia after bleeding into the anterior portion of the left basal ganglia. Neuropsychological examination included tests of attention, executive function, working memory, recall, and recognition of verbal and non-verbal material, and recall from remote semantic and autobiographical memory. The patient's MRI and those of other published cases of basal forebrain amnesia were reviewed to specify which structures within the basal forebrain are crucial for amnesia.

Results-Attention and executive function were largely intact. There was anterograde amnesia for verbal material which affected free recall and recognition. With both modes of testing the patient produced many false positive responses and intrusions when lists of unrelated words had been memorised. However, he confabulated neither on story recall nor in day to day memory, nor in recall from remote memory. The lesion affected mainly the nucleus accumbens, but encroached on the inferior limb of the capsula interna and the most ventral portion of the nucleus caudatus and globus pallidus, and there was evidence of some atrophy of the head of the caudate nucleus. The lesion spared the nucleus basalis Meynert, the diagnonal band, and the septum, which are the sites of cholinergic cell concentrations.
\end{abstract}

Conclusions-It seems unlikely that false positive responses were caused by insufficient strategic control of memory retrieval. This speaks against a major role of the capsular lesion which might disconnect the prefrontal cortex from the thalamus. It is proposed that the lesion of the nucleus accumbens caused amnesia. (F Neurol Neurosurg Psychiatry 1999;67:163-168)

Keywords: amnesia; basal forebrain; nucleus accumbens

Correspondence to:

Dr G Goldenberg,

Neuropsychologische

Abteilung, Krankenhaus

München Bogenhausen,

Englschalkingerstrasse 77, D

81925 München, Germany.

Telephone 0049899270

2106; fax 0049899270

2089; email

Georg.Goldenberg@1rz.tum.de

Received 20 October 1998 and in revised form

12 January 1999

Accepted 19 January 1999 and anterior portions of the thalamus can cause amnesia. ${ }^{2-7}$ The evidence for a selective role of the basal forebrain in human memory is weaker and more indirect. It has originally been derived from degeneration of cholinergic cells within the basal forebrain in Alzheimer's disease. ${ }^{89}$ As amnesia is a core symptom of Alzheimer's disease it has been concluded that basal forebrain lesions can cause amnesia. This conclusion is not compelling as neuronal degeneration in Alzheimer's disease affects medial temporal structures as well. ${ }^{10}{ }^{11}$ More direct evidence for basal forebrain amnesia is provided by patients with amnesia after circumscribed damage to only the basal forebrain. ${ }^{12-22}$ In most of them, the lesion was caused by haemorrhage from anterior communicating artery aneurysms and subsequent infarction of perforating arterial branches or Heubner's recurrent artery. ${ }^{12-14} 16{ }^{17}{ }^{19-22}$ However, subarachnoidal or intraventricular haemorrhage may cause hydrocephalus and diffuse brain damage. This raises the possibility that at least some of the symptoms of these patients are due to diffuse brain damage rather than to the basal forebrain lesion. ${ }^{23}$

The anatomicoclinical relation of basal forebrain amnesia is further complicated by the proximity of the basal forebrain to the frontal lobe. Lesions from anterior artery aneurysms often affect the orbital and medial frontal lobe. ${ }^{12172425}$ Disinhibition or unconcern related to frontal lobe pathology may distort or conceal the amnesic syndrome. ${ }^{16}$ Particularly, confabulations which are a frequent feature of basal forebrain amnesia have been related to accompanying frontal lobe pathology rather than to the basal forebrain lesion itself. ${ }^{26}$

The uncertainty of the anatomicoclinical relation increases when localisation within the basal forebrain is considered. Inspired by the parallel with Alzheimer's disease, some authors have considered damage to cholinergic cells in the septum, the diagonal band, or the nucleus basalis of Meynert as being the cause of amnesia. ${ }^{12}{ }^{18}$ An alternative account holds that lesions of fibre tracts rather than cells are crucial for amnesia. ${ }^{1520}$ The basal forebrain is traversed by the inferior and anterior thalamic peduncles which connect the dorsomedial nucleus of the thalamus with the amygdalae and with the prefrontal cortex. Amnesia may be caused by interruption of an amygdalathalamic-prefrontal loop rather than by basal forebrain damage itself. ${ }^{1527}$

In this paper we describe a patient with amnesia from a circumscribed basal forebrain lesion which did not extend into the frontal 
A
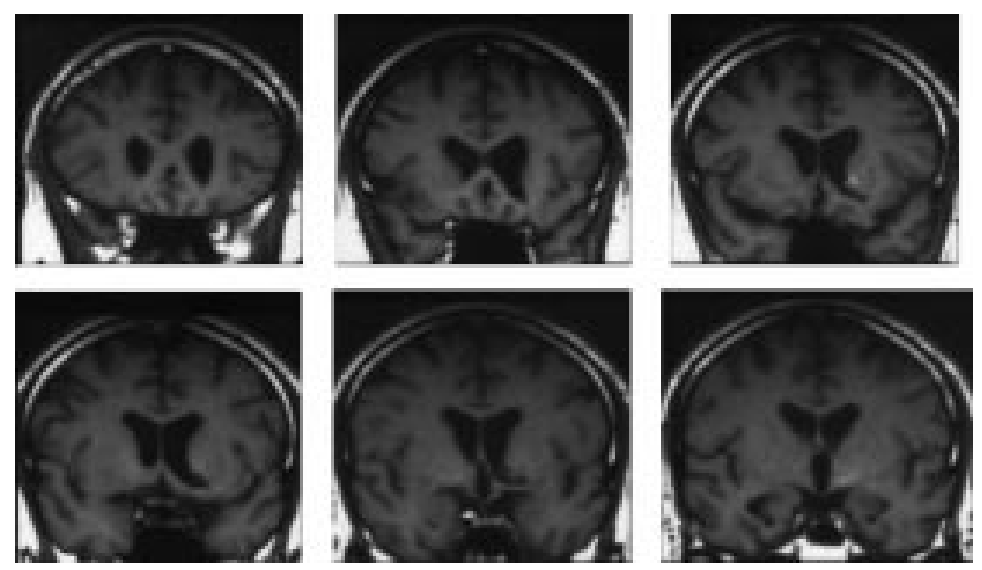

B

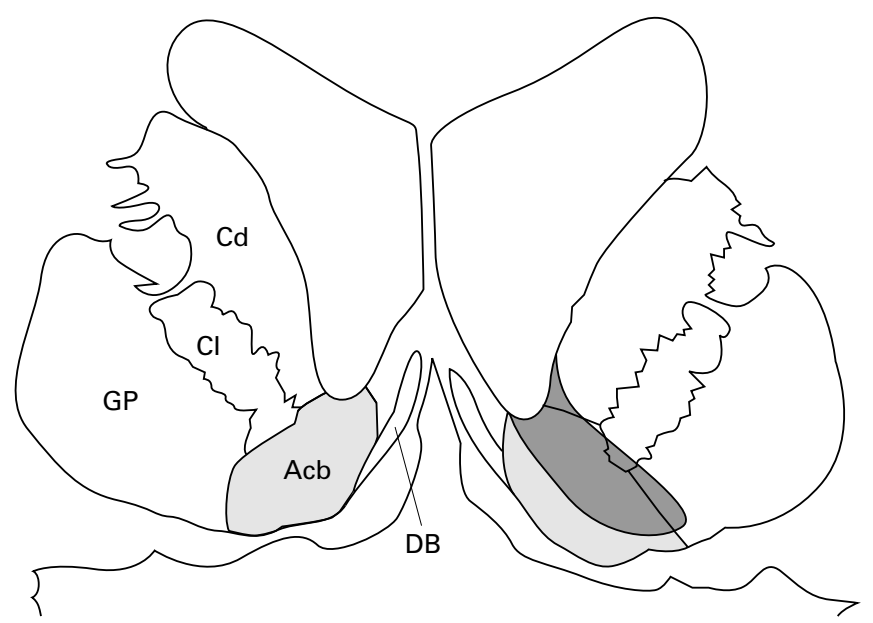

(A) T 1 weighted MRI of the lesion. (B) Anatomical scheme of the centre of the lesion, corresponding to the leftmost image of the bottom row of the MRI. The right side of the figures corresponds to the left side of the brain. GP=globus pallidus; Cd=caudate nucleus; $A c b=$ nucleus accumbens; $C I=$ capsula interna; $D B=$ diagonal band.

lobes and which largely spared structures rich on cholinergic cells.

\section{Case report}

The patient was a 55 year old right handed engineer who held a managing position in an international computer company. He had arterial hypertension. In July 1996 he became somnolent and confused. On emergency admission, CT showed bleeding into the anterior portion of the left basal ganglia with invasion into the left frontal horn of the lateral ventricle. No source of bleeding could be identified on angiography. During the subsequent weeks the medical records noted mild right sided weakness, word finding difficulties, and paraphasia. His ability to store new information was severely defective and he was disoriented to time.

He was admitted as an outpatient to our department in October 1996. The hemiparesis had resolved and conversation was inobstrusive. He was fully oriented, but complained of memory problems: He rated himself as very poor at remembering names, places, and the content of conversations. His spouse confirmed that he often enquired about details which had been talked about only a few minutes ago. In addition he noted an impoverishment of his autobiographical memories and a loss of professional knowledge. He could not remember geographical facts, names of other companies, mathematical formulae, or phone numbers which he had known by heart before. He said that he had lost his previous knowledge of foreign languages. He had to translate laboriously even English which had been the everyday language in his job. Visiting a place where he had spent several holidays, his wife and he noted that he had difficulties in finding familiar routes. As well as his memory problems the patient complained of a loss of libido and of a flattening of emotional reactions. $\mathrm{He}$ said: "There is nothing which makes me really happy or really sad. It's all far away".

Neurological examination showed only a slight reduction of fine motor skill of the right hand, which disappeared completely during the subsequent weeks.

NEURORADIOLOGICAL EXAMINATION

Brain MRI (figure) showed a sharply demarcated, slit-like, lesion which ran from the bottom of the left frontal horn in a slightly curved way laterally. The caudal limit of the lesion was at the level of the anterior commissure. The lesion destroyed a large portion of the nucleus accumbens and encroached on the inferior limb of the capsula interna and the most ventral portions of the anterior nucleus caudatus and globus pallidus. There was no general enlargement of ventricles, but the wall of the left frontal horn was slightly widened and flattened, indicating some atrophy of the head of the caudate nucleus.

Tc-99-HMPAO SPECT showed hypoperfusion of left basal ganglia ( $92 \%$ of homologuous right brain region), left frontal cortex $(91 \%)$ and left basal and medial temporal cortex $(91 \%$ and $90 \%)$.

\section{NEUROPSYCHOLOGICAL EXAMINATION}

Attention

The patient scored well within the normal range on a battery of computerised tests probing reaction time, speed of visual scanning, divided attention, and shifting of attention. ${ }^{28}$ His attention/concentration index value on the WMS- $\mathrm{R}^{29}$ was 111 .

\section{Language}

In German, his native language, speech was well articulated, fluent, and syntactically correct. Only when talking about difficult and complex matters did his expression become imprecise and circumstantial with occasional confusions of low frequency words. He perfectly named 20 highly familiar items from the Snodgrass-Vanderwart pictures ${ }^{30} 31$ but made two errors for 20 unfamiliar items ("perhaps a goose?" for ostrich, and skittle for spinning top). Knowledge of second languages was not assessed.

\section{Intelligence}

On a multiple choice lexical decision test with words of decreasing frequency, ${ }^{32}$ reflecting pre- 
Anterograde memory

\begin{tabular}{|c|c|c|}
\hline Test & Result & Comment \\
\hline \multicolumn{3}{|l|}{ Rivermead behavioural memory } \\
\hline Profile score / screening score & $15 / 6$ & Defective \\
\hline \multicolumn{3}{|l|}{ WMS-R index score: } \\
\hline Verbal memory & 83 & Below average \\
\hline Visual memory & 104 & Average \\
\hline Delayed recall & 78 & Below average \\
\hline \multicolumn{3}{|l|}{ Berlin amnesia test z scores: } \\
\hline Verbal & -3.23 & Severely defective \\
\hline Numeric & -0.12 & Average \\
\hline Recall/recognition verbal & -1.88 & Below average \\
\hline Recall/recognition numeric & -1.06 & Average \\
\hline \multicolumn{3}{|l|}{ Recognition memory: } \\
\hline $\begin{array}{l}25 \text { words: immediate/delayed } \\
\text { (correct/false positive) }\end{array}$ & $6(16 / 10) / 5(21 / 16)$ & Severely defective \\
\hline $\begin{array}{l}25 \text { faces: immediate/delayed } \\
\text { (correct/false positive) }\end{array}$ & $18(19 / 1) / 15(17 / 2)$ & Average \\
\hline \multicolumn{3}{|l|}{ CVLT: } \\
\hline List a: 5 trials (total intrusions) & $4 / 4 / 7 / 6 / 6(1)$ & Defective \\
\hline List b & 5 & \\
\hline $\begin{array}{l}\text { List a: recall after interference } \\
\text { /delayed (intrusions) }\end{array}$ & $0(5) / 1(1)$ & Severely defective \\
\hline $\begin{array}{l}\text { Delayed recognition of list a (false } \\
\text { positive) }\end{array}$ & $14(9)$ & Severely defective \\
\hline \multicolumn{3}{|l|}{$\begin{array}{l}\text { Learning of eight paired associates ( } 4 \\
\text { trials): }\end{array}$} \\
\hline Words & $0 / 0 / 2 / 2$ & Defective with exception of trial 1-3 of face-name associations \\
\hline Objects & $2 / 3 / 4 / 4$ & \\
\hline $\begin{array}{l}\text { Face- name (delayed after } 48 \\
\text { hours) }\end{array}$ & $5 / 6 / 7 / 7(0)$ & \\
\hline $\begin{array}{l}\text { Story recall ( } 24 \text { units of information): } \\
\text { immediate / delayed }\end{array}$ & $9 / 1$ & Below average / severely defective \\
\hline \multicolumn{3}{|l|}{$\begin{array}{l}\text { Story recall ( } 16 \text { units of information): } \\
\text { immediate / after } 30 \mathrm{~min} \text { / after } 24 \\
\text { hours }\end{array}$} \\
\hline Emotional story (with cueing) & $8.5 / 0(5) / 0(4.5)$ & All values severely defective \\
\hline Neutral story (with cueing) & $3 \star / 0(2) / 0(1)$ & \\
\hline $\begin{array}{l}\text { Taylor figure recall: } \\
\text { immediate/delayed }\end{array}$ & $28 / 23$ & Average \\
\hline
\end{tabular}

Below average $=<25$ th percentile; defective $=<5$ th percentile; severely defective $=<1$ st percentile.

*After immediate recall the neutral story had been presented for a second learning trial which yielded an immediate recall score of 5 .

morbid intelligence level, his score was equivalent to an IQ of 124 . On the German WAIS-R ${ }^{33}$ his performance IQ was 121 and his verbal IQ was 100 . In the verbal part the poorest result was on arithmetic (scaled score 6) whereas the other subtests yielded scaled scores between 10 and 13. In the performance part scaled scores on picture completion and block design were superior (18 and 15) and the other scaled scores ranged from 10 to 12 .

Executive functions

He obtained normal scores on the modified Wisconsin card sorting test, ${ }^{34}$ the Tower of London test, ${ }^{35}$ and the six elements test. ${ }^{36}$ Design fluency ${ }^{37}$ was normal (25/3 minutes: 40th percentile of normal controls). Fluency for words with a given initial letter was lower albeit still within the normal range (20/3 minutes: 15th percentile).

Primary and working memory

Visual span was above average (WAIS-R: forwards 98 th percentile; backwards 90 th percentile) and digit span average (forwards $51 \mathrm{st}$ percentile, backwards 31 st percentile). A weakness of verbal working memory manifested itself in tests which demand both maintainance and processing of verbal information-for example, reading $\operatorname{span}^{38}$ ( $\operatorname{span}=2$, 6th percentile) or a computerised test of verbal working memory $^{28}$ (level 3, 1st percentile). The poor result on WAIS-R arithmetic may also relate to this weakness.
Anterograde memory

A selection of tests of anterograde memory is given in the table. In accordance with the patient's complaints, the reports of his spouse and our findings, the Rivermead behavioural memory test ${ }^{39}$ confirmed ecologically significant memory impairment. Recall and recognition of verbal information were severely defective. By contrast, recall and recognition of nonverbal visual information were normal. On the Berlin amnesia test, ${ }^{40}$ which provides normative data for comparing recall and recognition, recognition of words seemed to be less affected than free recall. A story with emotional content was better recalled than a neutral one. A notable feature of his performance on tests of free recall of words was the production of intrusions. For example, in recall after interference of a German adaptation of the California verbal learning test $\left(\right.$ CVLT) ${ }^{41}$ he produced more intrusions than list words. Likewise, the poor scores on verbal recognition memory were largely due to false positive responses. Indeed, he recognised roughly equal numbers of faces and words, but whereas the total score on face recognition was normal, the score on verbal recognition fell to near chance levels because of the many false positive responses. However, he confabulated neither in story recall nor in daily life.

\section{Semantic memory}

A preservation of basic semantic knowledge was manifested by his average score on the 
WAIS-R subtest information and by the absence of significant naming difficulties. However, he did have some word finding difficulties for unfamiliar items (see above) and categorical fluency ${ }^{42}$ was mildly impaired with the exception of musical instruments (animals: 13/1 min; birds: 4/1 min; household items: 15/1 min; musical instruments: $12 / 1 \mathrm{~min}$ ). Drawing familiar objects from memory was good. We could not assess his professional knowledge but he credibly assured us that it had become severely defective. On a famous faces test which presents faces of 15 famous persons from each decade and asks for the famous persons' names and for semantic information about them his scores were at the 5 th percentile of age matched controls for persons famous between 1966 to 1975 , below the 1st percentile for 1976 to 1985 , and between the 5 th and 25th percentile for 1945 to 1965 and after 1986. In this test he never produced a wrong name and only once wrong semantic information ("American Secretary for Foreign Affairs" for Winston Churchill). All other errors were constituted by "don't know" responses.

\section{Autobiographical memory}

The patient complained of an impoverishment of his entire autobiographical memory. On the autobiographical memory interview ${ }^{43}$ knowledge about autobiographical facts was good for childhood and for recent time (17.5 and 18 out of 21) but defective for early adulthood $(11 / 21)$. Recall of autobiographical incidents was borderline to abnormal for all time periods and showed a similar time gradient with the most severe loss for early adulthood (childhood: 6/9; early adulthood: $1 / 9$; recent time: 4/9). Recall of autobiographical episodes was further explored with a modified Crovitz technique. ${ }^{44} \mathrm{He}$ was presented with 60 cue words (for example, train, friendship, hostility, swim, laugh, destroy). He was asked to produce an autobiographical episode related to each word and to say from which period of his life it stems. Episodes were rated for specifity and richness. He produced only 35 episodes, which is below average. In addition, he gave 12 general statements without episodic character, and refused to produce more specific information when requested to do so. In parallel to the famous faces test, production was poorest for the period from 1976 to 1985 . We could not check the veracity of those episodes which he produced but they did seem to be plausibly true memories.

\section{Discussion}

The patient had a severe anterograde memory deficit for verbal material affecting free recall and recognition. With both modes of testing a significant source of errors was constituted by false positive responses and intrusions. However, the patient confabulated neither on story recall nor in day to day memory. Retrograde memory was impoverished for both semantic and autobiographical information. On tests of retrograde memory he virtually never pro- duced wrong information but stated that he did not know the response.

Primary memory for verbal material was within normal limits. Only when he had to maintain and simultaneously process verbal material his performance fell below normal values. He scored normally on tests of executive functions. Verbal fluency was lower than graphic fluency, and there were some word finding problems for unfamiliar items. These language difficulties were, however, far too mild to plausibly explain his severe amnesia for any verbal material.

The responsible lesion was unilaterally left sided. It had its centre in the nucleus accumbens but encroached on the inferior limb of the internal capsula and the ventral portion of the globus pallidus and nucleus caudatus. There was evidence of some atrophy of the head of the caudate nucleus and of frontal and temporal hypoperfusion.

Similar to patients with unilaterally left sided medial temporal or thalamic lesions ${ }^{46}$ and two other patients with strictly unilateral left sided basal forebrain lesions ${ }^{1521}$ he had amnesia only for verbal material and no significant deficits of general intelligence, attention, or executive function. This constellation is unlikely to be a manifestation of diffuse brain damage. ${ }^{23}$ We therefore feel justified to interprete his amnesia as a sequel of the circumscribed basal forebrain lesion.

In addition to the anterograde memory deficit, he had difficulties recalling premorbidly acquired autobiographical and semantic information. As these were tested mainly verbally, it is not clear whether the deficit affected visual memory as well. Drawing of objects from memory was normal, but the husband and his wife reported some difficulties with retrieval of topographical memories. Recall of autobiographical episodes and of famous persons was poorest for the years from 1976 to 1985 when he was between 35 and 45 years old. Presumably, the poor result for "early adulthood" in the autobiographical memory interview included the same period. This gap may be an enhancement of the paucity of memories from this period of life which has been documented in normal subjects older than 50 years. ${ }^{46}$

If anterograde and retrograde amnesia had a common cause, this would be most likely to be a defect of retrieval rather than of memory consolidation or storage. There are, however, other patients with basal forebrain amnesia in whom premorbidly acquired autobiographical $^{20} 21$ and semantic ${ }^{20}$ memory were normal. Apparently the combination of anterograde and retrograde memory loss is not an invariable feature of basal forebrain amnesia. We think, however, that the published data on retrograde memory loss in basal forebrain amnesia are too scarce too permit any definite conclusions regarding their underlying mechanisms. Further discussion will concentrate on the anterograde verbal memory deficit.

The absence of a general weakness of executive function does not rule out the possiblity of a specific weakness of executive control of verbal memory. We discuss this possibility, and 
then the location of the critical lesion within the basal forebrain.

FALSE RESPONSES AND STRATEGIC CONTROL OF MEMORY RETRIEVAL

The patient produced numerous intrusions in recall of word lists, and the inaccuracy of his recognition memory for words was entirely due to the high number of false positive responses. At the same time, he confabulated neither on story recall, nor in recall from remote semantic and autobiographical memory, nor in daily life. False responses were thus restricted to memory for word lists. For these words, the decision whether a word coming to mind during recall was correct or not could be based on nothing else but on memory of this particular word's occurrence in the word list. There was no way to infer the plausibility of the decision from partial recall of the memorised material or from preserved remote memory. By contrast, tests which did not provoke false responses asked either for memory of organised verbal information (story recall, autobiographical episodes), or for recall of names and information with a defining relation to pictures presented during recall (famous persons). In these tests, he could exploit partial recall of the memorised material or preserved remote memory for judging the plausibility of information coming to mind.

On this account, supervisory control of recall was intact. He used available knowledge for controlling the plausibility of information coming to mind. The source of false responses might be sought in a general enhancement of "feeling of familiarity" ${ }^{24}$ which levelled the signal to noise ratio between memorised items and items which were similar but had not been presented. Feelings of familiarity were assigned indistinctly to any word that came to mind during recall and misled his responses when he had no external evidence for checking the credibility of this feeling. False responses may also have resulted from a strategic decision at the level of supervisory control. He may have opted for a liberal response bias whenever he had no resources for estimating the plausiblity of responses. In any case, intrusions and false positive responses do not indicate a failure of supervisory control of memory.

IS THE NUCLEUS ACCUMBENS A CRITICAL STRUCTURE FOR HUMAN MEMORY?

The basal forebrain consists of three functionally distinct compartments ${ }^{47}$ : the corticopetal, mainly cholinergic, system, the extended amygdalae, and the ventral striatopallidal system. Cholinergic cells are concentrated in the septum, the diagonal band, and the nucleus basalis. ${ }^{48}$ The extended amygdalae stretch from the centromedial nuclei of the amygdalae medially and rostrally through the substantia innominata into the medial portion of the nucleus accumbens where they join the ventral striatopallidal system. The ventral striatopallidal system is constituted rostrally by the nucleus accumbens and caudally by subcommissural continuations of putamen and globus pallidus. The nucleus accumbens occupies a central position in the functional interplay between these components of the basal forebrain and between the basal forebrain and other brain regions. It constitutes a junction between extended amygdalae and the ventral striatopallidal system and it has efferent connections to the corticopetal system. It is therefore able to modulate cholinergic output. ${ }^{47}$ The nucleus accumbens sends efferents to the hypothalamus, substantia nigra, autonomic brainstam nuclei, and the pallidum, which provides a connection to the dorsomedial nucleus of the thalamus. ${ }^{49}$ It receives afferent projections from dopaminergic midbrain nuclei and intralaminar thalamic nuclei, from the hippocampus and basolateral amygdalae, and from the prefrontal, insular, and temporal association cortex. ${ }^{47-52}$ It is thus in a position to integrate inputs from multiple cortical and subcortical areas including the hippocampus and the amygdalae, and to exert modulatory influences on widespread cortical function.

Animal studies have suggested a role of the nucleus accumbens in memory. Rats with selective lesions of the nucleus accumbens have been found to fail on tests such as the Morris water maze or delayed win-shift foraging, which depend on mnemonic function and which are known to be sensitive to hippocampal lesions..$^{51-55}$ It has not, however, been settled whether these deficits are reflections of mnemonic dysfunction or of other behavioural disturbances. 50

Published studies of basal forebrain amnesia lend credibility to a role of the nucleus accumbens in human memory. In a group study of patients with operated anterior communicating artery aneurysms, Irle et $a l^{17}$ found memory disturbances only in patients with "combined basal forebrain-striatum" lesions. The nucleus accumbens forms part of the ventral striatum. Nucleus accumbens lesions were visible on MRI or CT in several published cases of basal forebrain amnesia. ${ }^{12-14} 18{ }^{20}$ In a further patient ${ }^{15}$ the lesion affected the ventral pallidum and in two other patients MRI showed atrophy of the caudate nucleus. ${ }^{21}{ }^{22}$ It is notable that in some of these cases, ${ }^{13152122}$ as well as in our patient, the nucleus basalis, septum, and diagonal band, which have the greatest concentration of corticopetal cholingergic cells, seem to be unaffected.

In summary, there seems to be rather convincing evidence that affection of parts of the striatopallidal system makes an important contribution to basal forebrain amnesia. ${ }^{17}$ The evidence for the nucleus accumbens as critical structure is less unequivocal, but does seem to deserve further studies in animals and humans. ${ }^{51}$

Because the patient's lesion encroached on the anterior limb of the internal capsula our finding would be compatible with the hypothesis that lesions of fibre tracts rather than cell bodies are responsible for amnesia from extrahippocampal lesions. ${ }^{15}{ }^{27}$ In particular, the capsular lesion may have damaged the anterior thalamic peduncle which connects the dorso- 
medial nucleus of the thalamus to the prefrontal cortex. It should be noted, however, that the inferior thalamic peduncle which connects the basolateral amygdalae with the dorsomedial nucleus, runs caudally from the anterior commissure and seemed not to be affected. Interruption of fibres between the prefrontal cortex and thalamus may disconnect strategic processes supported by the frontal lobes from memory functions depending on the thalamus. ${ }^{57}$ However, as we have argued in the previous section, strategic control of memory processes seemed to be well preserved in our patient.

1 Zola-Morgan S, Squire LR. Neuroanatomy of memory. Ann Rev Neurosci 1993;16:547-63.

2 Zola-Morgan S, Squire LR, Amaral DG. Human amnesia and the medial temporal region: enduring memory impairment following a bilateral lesion limited to field CA 1 of the ment following a bilateral lesion limited to
hippocampus. $\mathcal{F}$ Neurosci $1986 ; 6: 2950-67$

3 Corkin S, Amaral DG, Gonzalez RG, et al. HM's medial temporal lobe lesion: findings from magnetic resonance imaging. F Neurosci 1997; 17:3964-79.

4 Goldenberg G, Wimmer A, Maly J. Amnesic syndrome with a unilateral thalamic lesion: a case report. $\mathcal{f}$ Neurol 1983;229:79-86.

5 Von Cramon DY, Hebel N, Schuri U. A contribution to the anatomical basis of thalamic amnesia. Brain 1985;108:9931008.

6 Clarke S, Assal G, Bogousslavsky J, et al. Pure amnesia after unilateral left polar thalamic infarct: topographic and sequential neuropsychological and metabolic (PET) correlations. F Neurol Neurosurg Psychiatry 1994;57:27-34.

7 Parkin AJ, Rees JE, Hunkin NM, et al. Impairment of memory following discrete thalamic infarction. Neuropsychologia 1994;32:39-52.

8 Whithehouse PJ, Price DL, Clark AW, et al. Alzheimer disease: evidence for selective loss of cholinergic neurons in disease: evidence for selective loss of cholinergic

9 Coyle JM, Price DL, DeLong MR. Alzheimer's disease: a disorder of cortical cholinergic innervation. Science 1983, 219:1184-90.

10 Braak H, Braak E. Neuropathological staging of Alzheimerrelated changes. Acta Neuropathol 1991;82:239-59.

11 Fibiger HC. Cholinergic mechanisms in learning, memory and dementia: a review of recent evidence. Trends Neurosci 1991;14:220-3.

12 Damasio AR, Graff-Radford NR, Eslinger PJ, et al. Amnesia following basal forebrain lesions. Arch Neurol 1985;42:26371

13 Phillips S, Sangalang V, Sterns G. Basal forebrain infarction: a clinicopathological correlation. Arch Neurol 1987;44: 1134-8.

14 Fukamachi A, Horikoshi T, Nagaseki Y, et al. Symmetrical bilateral low-density lesions in the area of supply by Heubner's arteries after aneurysm surgery. Acta Neurochir (Wien) ner's arteries after

15 Markowitsch HJ, Von Cramon DY, Hofmann E, et al. Verbal memory deterioration after unilateral infarct of the internal capsule in an adolescent. Cortex 1990;26:597-609.

16 De Luca J. Cognitive dysfunction after aneurysm of the anterior communicating artery. $\mathcal{F}$ Clin Exp Neuropsychol 1992;14:924-34.

17 Irle E, Wowra B, Kunert HJ, et al. Memory disturbances following anterior communicating artery rupture. Ann Neuro 1992;31:473-80.

18 Morris MK, Bowers D, Chatterjee A, et al. Amnesia following a discrete basal forebrain lesion. Brain 1992;115:182747.

19 Bondi MW, Kaszniak AW, Rapcsak SZ. Implicit and explicit memory following anterior communicating artery aneurysm rupture. Brain Cogn 1993;22:213-29.

20 Von Cramon DY, Markowitsch HJ, Schuri U. The possible contribution of the septal region to memory. Neuropsychologia 1993;31:1159-80.

21 Hanley JR, Davies ADM, Downes JJ, et al. Impaired recall of verbal material following rupture and repair of an anterior communicating artery aneurysm. Cogn Neuropsychol 1994; 11:543-78.

22 Weniger G, Markowitsch HJ, Irle E. Anterograde and retrograde mnemonic deficits after unilateral damage of neostriatal, ventral striatal and basal forebrain structures. Neurocase 1995;1:231-8.

23 Richardson JTE. Performance in free recall following rupture and repair of intracranial aneurysms. Brain Cogn 1989;10:210-26.

24 Delbercq-Derouesné J, Beauvois MF, Shallice T. Preserved recall versus impaired recognition. Brain 1990;113:1054recall

25 Dalla Barba G, Cappelletti JY, Signorini M, et al. Confabulation: Remembering another past, planning another future. Neurocase 1997;3:425-36.
26 Fischer RS, Alexander MP, D'Esposito M, et al. Neuropsychological and neuroanatomical correlates of confabulation. F Clin Exp Neuropsychol 1995;17:20-8.

27 Markowitsch HJ. Diencephalic amnesia: a reorientation towards tracts? Brain Res Rev 1988;13:351-70.

28 Zimmermann P, Fimm B. Testbatterie zur Aufmerksamkeitsprüfung (TAP). Freiburg: Psychologische Testsysteme, 1993.

29 Wechsler D. The Wechsler memory scale - revised. San Diego: Psychological Corporation, 1987.

30 Snodgrass JG, Vanderwart M. A standardized set of 260 pictures: norms for name agreement, image agreement, familiarity, and visual complexity. F Exp Psychol Learn Mem Cogn 1980;6:174-215.

31 Genzel G, Kerkhoff G, Scheffter S. PC-gestützte Standardisierung des Bildmaterials von Snodgrass und Vanderwart (1980). Neurolinguistik 1995;41-53.

32 Lehrl S. Mehrfachwahl - Wortschatz - Intelligenztest. MWT-B. Erlangen: Verlag D Straube, 1977

33 Tewer U. HAWIE-R: Hamburg-Wechsler-Intelligenztest für Erwachsene. Bern: Huber, 1991.

34 Nelson HE. A modified card sorting test sensitive to frontal lobe defects. Cortex 1976;12:313-24.

35 Shallice T. Specific impairments of planning. Phil Trans $R$ Soc Lond B Biol Sci 1982;298:199-209.

36 Shallice T, Burgess PW. Deficits in strategy application following frontal lobe damage in man. Brain 1991;114:72741 .

37 Regard M, Strauss E, Knapp P. Children's production on verbal and non-verbal fluency tasks. Percept Mot Skills 1982;55:839-44.

38 Daneman $\mathrm{M}$, Carpenter PA. Individual differences in working memory and reading. Fournal of Verbal Learning and Verbal Behaviour 1980;19:450-66.

39 Wilson B, Cockburn J, Baddeley A. The Rivermead behavioural memory test. Reading: Thames Valley Test Company, 1985.

40 Metzler P, Voshage J, Rösler P. Berliner Amnesietest (BAT). Göttingen: Hogrefe, 1992.

41 Ilmberger J. German version of the California verbal learning tests. München: Institut für Medizinische Psychologie der Universität, 1988

42 Hodges JR, Patterson K. Is semantic memory consistently impaired early in the course of Alzheimer's disease? Neuroanatomical and diagnostic implications. Neuropsychologia 1995;33:441-60.

43 Kopelman MD, Wilson BA, Baddeley AD. The autobiographical memory interview: a new assessment of autobiographical and personal semantic memory in amnesic patients. F Clin Exp Neuropsychol 1989;11:724-44.

44 Robinson JA. Sampling autobiographical memory. Cogn Psychol 1976;8:578-95.

45 Milner B. Interhemispheric differences in the localization of psychological processes in man. Br Med Bull 1971;27:272-

6 Rubin DC, Wetzler SE, Nebes RD. Autobiographical memory across the lifespan. In: Rubin DC, ed. Autobiographical memory. Cambridge: Cambridge University Press, 1986:202-24.

47 Alheid GF, Heimer L. New perspectives in basal forebrain organization of special relevance for neuropsychiatric disorders: the striatopallidal, amygdaloid, and corticopetal components of substantia innominata. Neuroscience 1988; 27:1-39.

48 Mesulam MM, Mulson EJ, Levey A, et al. Cholinergic innervation of cortex by the basal forebrain: cytochemistry
and cortical connections of the septal area, diagonal band nuclei, nucleus basalis (substantia innominata) and hypothalamus in the rhesus monkey. f Comp Neurol pothalamus in the

49 Alexander GE, DeLong MR, Strick PL. Parallel organization of functionally segregated circuits linking basal ganglia and cortex. Ann Rev Neurosci 1986;9:357-81.

50 Floresco SB, Seamans JK, Phillips AG. Differential effects of lidocaine infusions into the ventral CA1/subiculum or the nucleus accumbens on the acquisition and retention of spatial information. Behav Brain Res 1996;81:163-71.

51 Setlow B. The nucleus accumbens and learning and memory. $\mathcal{F}$ Neurosci Res 1997;49:515-21.

52 Redish AD, Touretzky DS. Cognitive maps beyond the hippocampus. Hippocampus 1997;7:15-35.

53 Annett LE, McGregor A, Robbins TW. The effects of ibotenic acid lesions of the nucleus accumbens on spatial learning and extinction in the rat. Brain Res 1989;31:23142 .

54 Sutherland RJ, Rodriguez AJ. The role of the fornix/fimbria and some related subcortical structures in place learning and memory. Behav Brain Res 1989;32:265-77.

55 Seamans JK, Phillips AG. Selective memory impairments produced by transient lidocaine-induced lesions of the nucleus accumbens in rats. Behav Neurosci 1994;108:45668.

56 Gal G, Joel D, Gusak O, et al. The effects of electrolytic lesion to the shell subterritory of the nucleus accumbens on delayed non-matching-to-sample and four-arm baited eight-art radial-maze tasks. Behav Neurosci 1997;111:92103.

57 Warrington EK, Weiskrantz L. Amnesia: a disconnection syndrome? Neuropsychologia 1982;20:233-48. 


\section{LETTERS TO THE EDITOR} Magnetic resonance imaging and
vertebral artery dissection

Since the advent of advanced radiological modalities such as MRI and magnetic resonance angiography (MRA), dissections of cervical arteries are increasingly recognised as a common cause of stroke in young adults. Auer $e t a l^{1}$ recently advocated MRA as the initial diagnostic tool for vertebral artery dissection. Conventional angiography might be avoided altogether in subjects with a suspicious history and MRA images suggestive of a dissection (double lumen or mural haematoma). ${ }^{1}$ The sensitivity of MRA for the diagnosis of vertebral artery dissection was
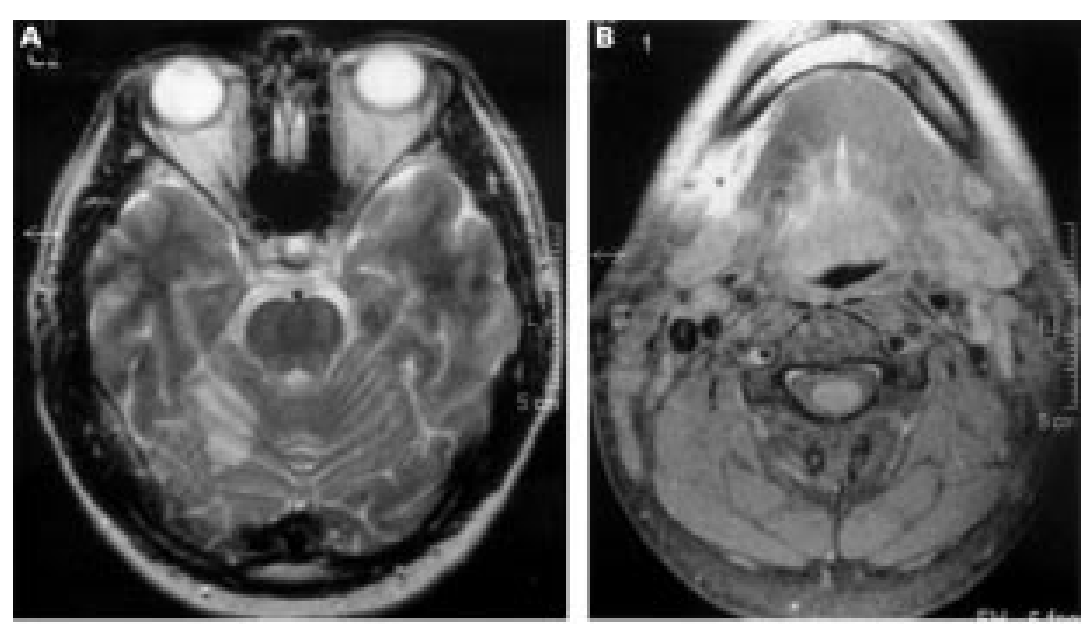

c
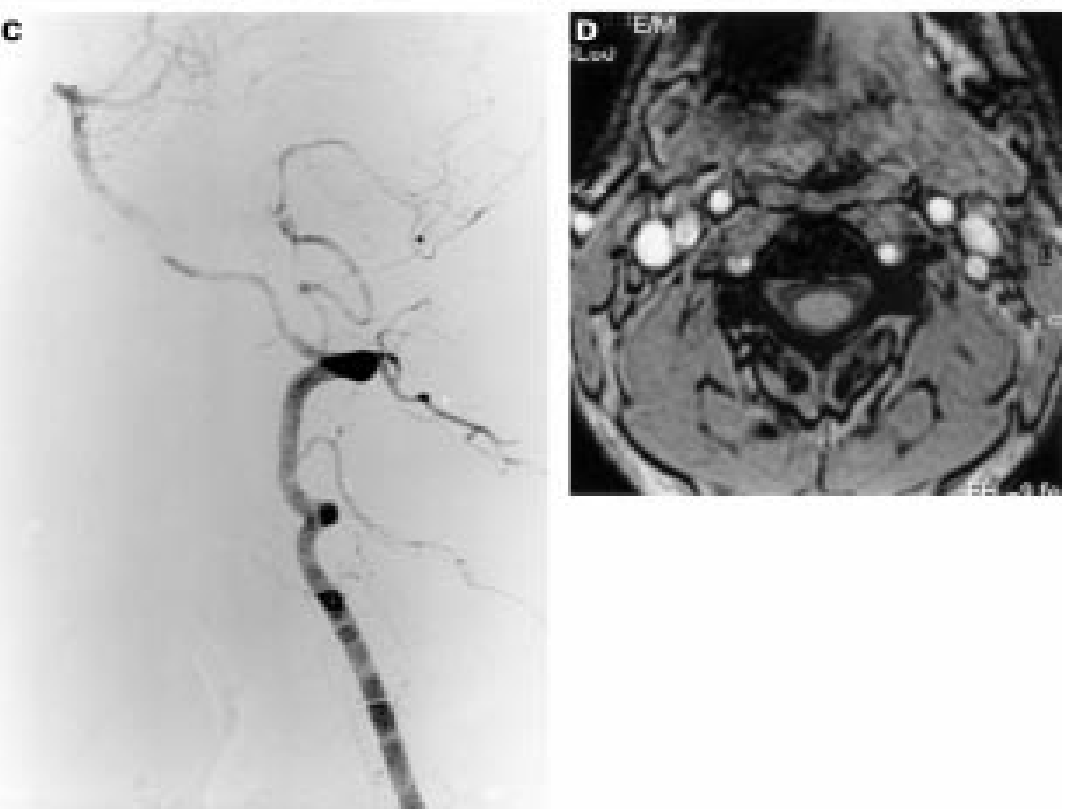

(A) T2 weighted fast spin echo image showing high signal intensity in the right cerebellar hemisphere, indicative for a recent infarct. The older infarct cannot be seen on this section. (B) Axial T1 weighted fast spin echo image with fat saturation at the level of the base of the tongue, showing a semilunar area with high signal intensity around the flow void in the right vertebral artery. (C) Selective contrast injection in the right vertebral artery shows no abnormalities. The remainder of the intra-arterial angiography of the cervical and cranial arteries was also normal. (D) Axial three dimensional time of flight technique, acquired in the axial plane image at the same level showing high signal intensity at the same location as in $B$. excellent $(100 \%){ }^{2}$ The sensitivity was considerably better in the hands of Auer et al, rate in specificity (true negative considered because all patients had vertebral artery dissection. The following case report illustrates that care must be taken to avoid

A 47 year old male pilot suddenly experienced clumsiness and slight loss of strength in the right arm and leg during a long distance flight, while he stooped forward. During the following hours, he developed a global headache without irradiation to the neck, but the history was unremarkable, except for a 3 hour period of horizontal diplopia which suddenly developed 3 months earlier. He had never smoked. Family history was negative for confessed that he had recently picked up the habit of gargling his throat with toothpaste only $20 \%$ in one study, but the specificity was diagnosis of vertebral artery dissection.

twice a day, always with his neck in extreme retroflexion.

General physical examination ( 8 hours after onset of symptoms) was normal. Neurological examination showed minimal paresis and impaired dexterity of the right hand, mild circumduction of the right leg, and an insecure tandem gait. An MRI (including T1 weighted spin echo images with and without fat suppression, and proton density and T2 weighted fast spin echo sequences, performed on a 1.5 Tesla whole body MRI system) performed several hours later visualised both a fresh and an old right sided cerebellar infarct (figure A). In addition, MRI showed an irregular right vertebral artery in which a patent lumen was partially surrounded by a semilunar area of high signal intensity on T1 and T2 weighted images. On fat suppressed images, this area's high signal intensity persisted, excluding the possibility that it originated from perivascular fat. This image was suggestive of mural haematoma due to vertebral dissection (figure B). Because we were reluctant to base any treatment decisions (anticoagulants) merely on MRI findings, digital subtraction angiography was performed on the day of admission. This examination was normal (figure C). Shortly after this procedure, the patient developed vertigo and nystagmus which disappeared after 3 hours. Because we were puzzled by the discrepant findings on conventional angiography and MRI, we performed an MRA 4 days later. At this examination, the semilunar area of high signal intensity was found again (figure D), despite saturation of craniofugal and craniopetal flow respectively, which was applied to exclude the possibility that the high signal originated from flow in the periarterial venous plexus. Therefore, this examination was again suggestive of right vertebral artery dissection. An extensive search for other causes of stroke showed no abnormalities. Hence, due to the continuing discrepancy between conventional angiography and $M R I / M R A$, and due to the absence of any other cause of stroke, no certain diagnosis could be established.

In this patient, a diagnosis of right vertebral artery dissection was initially made given the clinical course with repeated episodes of ischaemia restricted to the vertebrobasilar system, as well as the suggestive MRI findings. ${ }^{1}$ We speculated that habitual gargling was a potential underlying cause, as neck retroflexion can cause cervical dissections. However, we had to reject this diagnosis in view of the normal conventional angiography, which remains the gold standard for diagnosing cervical artery dissection. ${ }^{3}$ In one series, ${ }^{2}$ conventional angiography was never falsely negative in patients with clinical signs or symptoms of vertebral artery dissection. The possibility that conventional angiography had nevertheless yielded a false negative result seems highly unlikely. In dissected arteries, MRI/MRA can detect intimal flaps, mural haematomas, or aneurysmal dilatations that are sometimes missed by conventional angiography, but even in such patients conventional angiography is never completely normal in the acute stage. Follow up examinations of patients with proven vertebral artery dissection indicate that the appearance of a dissected artery on conventional angiography can normalise in a substantial proportion of patients, but always after an interval of at least 1 to (usually) several weeks. ${ }^{1}$ Conventional angiography in our patient was performed on the day of admis- 
sion, directly after the "abnormal" $M R I$ and four days prior to the "abnormal" MRA, hence spontaneous resolution of the dissection is very unlikely. Therefore, we consider our MRI/MRA examinations falsely positive, and we hypothesise that the area of semilunar high signal intensity originated from a perivascular venous plexus, in which we were unable to saturate inflow of blood completely, presumably due to extremely slow flow.

Our "pilot study" illustrates the specificity problems of MRI/MRA for the diagnosis of vertebral artery dissection. Two anatomical structures surrounding vertebral arteries contribute to these problems. The first structure is the venous plexus that surrounds vertebral arteries. This structure may have a semilunar appearance, and slow flow in its lumen may give rise to high signal intensity on both MRI and MRA, creating an image suggestive of dissection. ${ }^{4}{ }^{5}$ It has been suggested that saturation slabs in conjunction with MRA completely suppress flow related high signal, thus distinguishing it from high signal from an intramural haematoma which cannot be suppressed by saturation slabs. ${ }^{45}$ The present case report illustrates that flow in this plexus cannot always be suppressed.

The second tissue that may falsely present as a dissection is fat that directly surrounds vertebral arteries. This fat also gives rise to high signal intensity, but using fat suppression techniques it can be readily differentiated from intramural haematoma. Furthermore, the usual diameter asymmetry of vertebral arteries, turbulence and magnetic susceptibility near sharp vessel turns can also cause false positive MRA results. ${ }^{2}$ In some patients, MRI cannot distinguish between intraluminal thrombus and intramural haematoma, leading to false conclusions.

Decisions based on false positive MRI MRA results can be hazardous due to the sometimes severe side effects of anticoagulants, the treatment that is recommended by some to prevent further ischaemic events. Another danger of a false positive diagnosis of vertebral dissection is that it may preclude the search for other causes of stroke that could be amenable to secondary prevention.

MRI/MRA remains important because it helps visualise ischaemic lesions and, in some patients, provides complementary morphological information to cerebral angiography. Furthermore, it is a non-invasive procedure, an important advantage over cerebral angiography which carries a morbidity and mortality risk. Our patient, who developed transient neurological deficits shortly after angiography, underscores this. Therefore, MRA can play a part in the diagnosis of vertebral artery dissection, provided that the pitfalls mentioned above are recognised to avoid false positive results. In case of doubt, cerebral angiography remains the gold standard for vertebral artery dissection.

B R BLOEM G J LAMMERS Department of Neurology

M A VAN BUCHEM

Department of Radiology, Leiden University Medical Centre, The Netherland

Correspondence to: Dr Bastiaan R Bloem, Department of Neurology, Leiden University Medical Centre, PO Box 9600, 2300 RC Leiden, The Netherlands. Telephone 003171 5262134; fax 003171 5248253; email bloem@rullf2.medfac.leidenuniv.n]

1 Auer A, Felber S, Schmidauer C, et al. Magnetic resonance angiographic and clinical features of extracranial vertebral artery dissection. $7 \mathrm{Neu}$ rol Neurosurg Psychiatry 1998;64:474-81.
2 Levy C, Laissy JP, Raveau V, et al. Carotid and Levy C, Laissy JP, Raveau V, et al. Carotid and
vertebral artery dissections: three-dimensional time-of-flight MR angiography and MR imag ing versus conventional angiography. Radiology 1994;190:97-103.

3 Hart RG. Vertebral artery dissection. Neurology 1988;38:987-9.

4 Miaux Y, Cognard C, Martin-Duverneuil N, et al. Flow related enhancement in the vertebral plexus mimicking an intramural hematoma. Am 7 Neuroradiol 1996;17:191-2.

5 Dumas JL, Stanescu R, Goldlust D, et al. Vertebral vein imaging with MR angiography. $A m \mathcal{F}$ Neuroradiol 1997;18:1190-2.

Catatonia due to central pontine and extrapontine myelinolysis: case report

Central pontine and extrapontine myelinolysis (CPEM) are recognised complications of hyponatraemia and its overly rapid correction. ${ }^{1}$ CPEM usually presents with spastic tetraparesis and pseudobulbar palsy. ${ }^{1}$ We describe a patient with CPEM in whom behavioural manifestations overshadowed corticospinal tract signs.

A 64 year old Chinese speaking woman with a history of episodic psychotic depression that had never required admission to hospital was admitted to a hospital because of vomiting and diarrhoea. Her general and neurological examination were normal. On admission she had a sodium concentration of $105 \mathrm{meq} / 1$. An infusion of $3 \%$ saline at a rate of $150 \mathrm{ml} /$ hour was given during 6 hours. Ten hours later her sodium was $134 \mathrm{meq} / 1$ and she was mute and tetraparetic. She seemed catatonic with motor perseveration. Transfer to our hospital was requested.

On admission her vital signs were normal. She was mute without any spontaneous volitional movements except for visual pursuit. She was tetraparetic and hyperreflexic with increased tone and bilateral Babinski's signs. CPEM was suspected. Admission MRI, EEG, and spinal fluid examination were normal. Over the next 2 days the reflexes normalised and the Babinski's signs disappeared but she continued to have mild diffuse weakness. She had waxy flexibility and assumed bizarre non-physiological postures consistent with catatonia. Psychogenic unresponsiveness was suspected and she was started on risperidone and sertraline. There
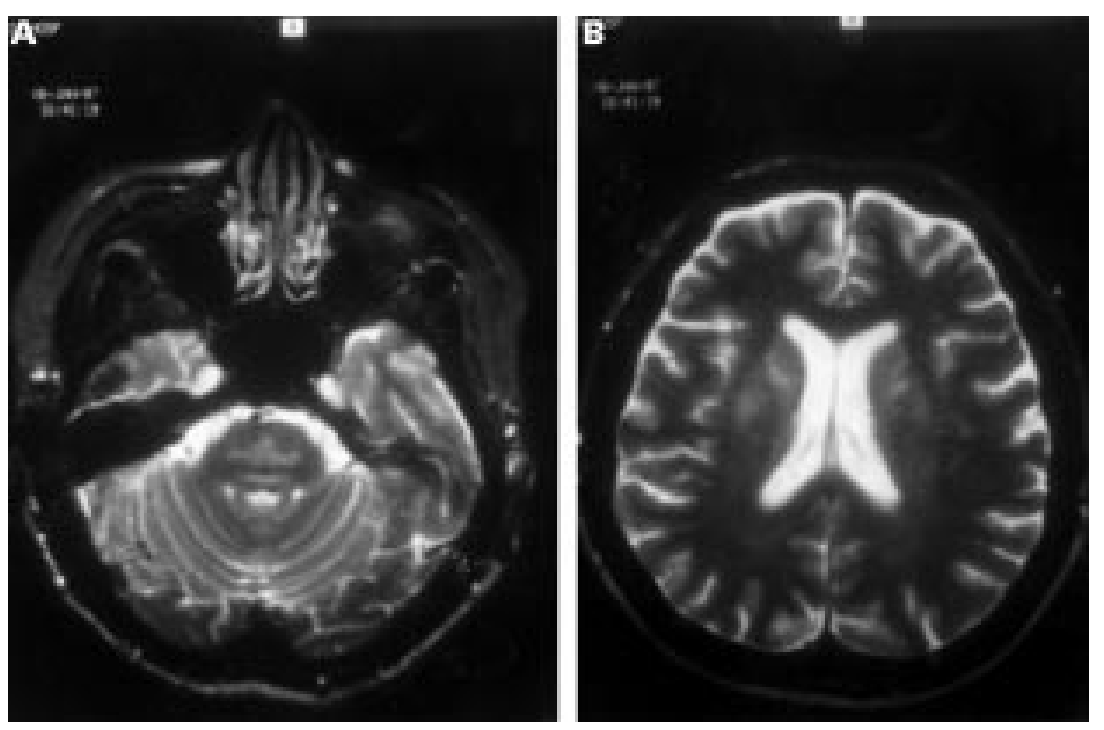

(A) Axial T2 weighted image showing prominent high signal intensity within the pons suggestive of central pontine myelinolysis. (B) Axial T2 image showing symmetric bilateral areas of high signal in the caudate and putamen suggestive of extrapontine myelinolysis.

was no benefit. Electroconvulsive therapy was proposed by a psychiatry consultant but was refused by the patient's family. The clinical picture was dominated by an akinetic mutism with marked catatonia. Catatonia due to CPEM was considered. A repeat MRI 12 days after the onset of symptoms showed high intensity areas in the pons, caudate, and putamen consistent with CPEM (figure A, B). Physical and occupational therapy were instituted and she gradually recovered over the next 2 weeks. She was transferred to a rehabilitation hospital where she recovered completely and returned to live independently. She has been followed up at the neurology clinic and has not shown any residual deficits.

CPEM usually presents with tetraparesis and pseudobulbar palsy. Unusual clinical presentations include extrapyramidal syndromes, ataxia, and neurobehavioural syndromes. Although psychiatric manifestations of CPEM have been recognised they usually manifest as an agitated delirium, or a pseudobulbar state with pathological laughing and crying. ${ }^{1}$ When present, neuropsychiatric symptoms are usually overshadowed by florid signs of brainstem and pyramidal tract dysfunction. ${ }^{23}$ Behavioural changes such as inappropriate affect, emotional lability, personality changes, paranoia, poor judgement, emotional incontinence, and disinhibition have been reported. ${ }^{12}$ Price and Mesulam described a case of pontine myelinolysis in which transient pyramidal signs were followed by confusion, restless behaviour, pressured tangential speech, and disinhibition. ${ }^{2}$ Our patient also had transient long tract signs but they were followed by a catatonic state. The extensive extrapontine myelinolysis present in our patient may explain the behavioural symptoms we encountered.

CPEM may present with unusual behavioural symptoms. At the onset of neurological deterioration MRI may be normal but subsequent imaging studies usually disclose the lesions. CPEM presenting with neuropsychiatric symptoms in patients with normal initial imaging studies might suggest a psychogenic aetiology. Corticospinal tract signs may be temporary. A strong index of suspicion for CPEM is required when patients with recent 
hyponatraemia present with behavioural changes. Akinetic mutism and catatonia may be the dominant clinical features in CPEM.

JULIO CHALELA

JORGE KATTAH

Department of Neurology, Georgetown University Medical Center, Washington DC, USA

Correspondence to: Dr Julio Chalela, 4000 Presidential Boulevard, Apartment 213, Philadelphia, PA 19131, USA. Telephone $001 \quad 215 \quad 878 \quad 3311$ email:jchalela@erols.com

1 Illowsky B, Laureno R. Pontine and extrapontine myelinolysis. Pontine and extrapontine myelinolysis: a neurologic disorder following rapid correction of hyponatremia. Medicin 1993;72:359-73.

2 Price $\mathrm{BH}$, Mesulam MM. Behavioral manifestations of central pontine myelinolysis. Arch Neutons of central pon $1987 ; 44: 671-3$.
rol

3 Laureno R, Illowsky B. Myelinolysis after correction of hyponatremia. Ann Intern Med correction of hyp
1997;126:57-62.

Association between butyrylcholinesterase $K$ variant and the Alzheimer type neuropathological changes in apolipoprotein $\mathrm{E} \& 4$ carriers older than 75 years

Apolipoprotein E (ApoE) $\varepsilon 4$ has a strong influence on the development of sporadic Alzheimer's disease in many ethnic populations. However, ApoE $\varepsilon 4$ is neither necessary nor sufficient for the development of Alzheimer's disease, suggesting that other genes increase the risk of Alzheimer's disease. One such new candidate is the butyrylcholinesterase (BChE) gene (BCHE). ${ }^{1} \mathrm{BChE}$ is associated with senile plaques (SPs) and neurofibrillary tangles (NFTs). Lehmann et at recently reported that the $\mathrm{K}$ variant of $B C H E$ $(B C H E-K)$ was associated with the development of Alzheimer's disease, especially in ApoE $\& 4$ carriers older than 75 years. ${ }^{1}$ A possible mechanism as to how $B C H E-K$ is related to Alzheimer's disease under the influence of ApoE $\varepsilon 4$ is the acceleration of Alzheimer type neuropathological changes. If $B C H E-K$ has an effect on the development of Alzheimer's disease in ApoE $\varepsilon 4$ carriers, the formation of Alzheimer type neuropathological changes may be accelerated by $B C H E-K$ in the ApoE $\varepsilon 4$ carriers.

We have examined genotypes of $B C H E$ and ApoE, and densities of the senile plaques (SPs), with dystrophic neurites (NPs), and neurofibrillary tangles NFTs in the brains from 51 patients with Alzheimer's disease and 90 non-demented subjects from a postmortem series of Japanese. Clinical and postmortem diagnosis of Alzheimer's disease was carried out as described previously. ${ }^{2}$ The densities of Alzheimer type neuropathological changes were quantified by averaging the counts of those in the hippocampus and superior temporal gyrus. Genotypes of $B C H E$ and ApoE in all patients were determined as described elsewhere. ${ }^{12}$ Genotypic and allelic distributions of $B C H E$ were analysed by $\chi^{2}$ test. The densities of the SPs, NPs, and NFTs, and ages at onset and durations of illness were compared among $B C H E$ genotypes with the Kruskal-Wallis test or MannWhitney $U$ test in total subjects, those with Alzheimer's disease, and non-demented subjects. We also examined these relations in the subgroups divided by the ApoE $\varepsilon 4$ status or the age of 75 years. Statistical significance was defined as two tailed probabilities of $<0.05$.

There were no significant differences in the frequency of $B C H E-K$ genotypes or alleles between patients with Alzheimer's disease ( 0.16 in allele frequency) and non-demented subjects (0.18), and in the total subjects, ApoE $\varepsilon 4$ carriers or non-ApoE $\varepsilon 4$ carriers, although a strong association of ApoE $\varepsilon 4$ alleles with Alzheimer's disease was found in this population $(\mathrm{p}=0.004)$. Genetic association of $B C H E-K$ genotypes with sporadic Alzheimer's disease was non-significant in all subjects older than 75 years, the ApoE $\varepsilon 4$ carriers older than 75 years, and non-ApoE $\varepsilon 4$ carriers older than 75 years. There was no genetic association of $B C H E-K$ with the densities of the SPs, NPs, or NFTs in the hippocampus and superior temporal gyrus in the total subjects, in the Alzheimer's disease or non-demented groups, or with ages at onset or duration of illness in Alzheimer's disease. However, when we divided total subjects into two subgroups with different ApoE $\varepsilon 4$ status, there was significant association between $B C H E-K$ and the density of the SPs and NPs in the superior temporal gyrus(STG) in the ApoE $\& 4$ carriers (SPs, $\mathrm{p}=0.04$; NPs, $\mathrm{p}=0.03$, data not shown). Further, we analysed the correlation between $B C H E-K$ and the densities of the SPs, NPs, and NFTs in the hippocampus and superior temporal gyrus in the ApoE $\& 4$ carriers older than 75 years and non-ApoE $\varepsilon 4$ carriers older than 75 years (table). There was a significant genetic association of $B C H E-K$ with the densities of the SPs, NPs, and NFTs in the STG in the ApoE $\varepsilon 4$ carriers older than 75 years. There was a decrease of severity of Alzheimer type neuropathological changes with $B C H E$ $K$. A similar trend was seen in the hippocampus though this did not reach significance.

Our results showed that $B C H E-K$ might have no effect on the development of sporadic Alzheimer's disease even in the ApoE $\varepsilon 4$ carriers or subjects older than 75 years. By contrast with a significant genetic association in patients confirmed at postmortem in the British population, ${ }^{1}$ there was no correlation in the Japanese population. Although our sample size was small, there were not even trends for a positive association in our study, suggesting that the lack of association was not due to small sample size. The frequency of $B C H E-K$ in our Japanese control population was 0.18 . This was not significantly different from that in the British population examined by Russ et al (0.20). ${ }^{3}$ However, the frequency of $B C H E-K$ in the British control population reported by Lehmann et al was 0.09, which was significantly lower than our results $(p=0.04) .{ }^{1}$ These findings indicate that the frequency of $B C H E-K$ and its genetic linkage with the development of Alzheimer's disease would be different among sample populations.

Our neuropathological study disclosed a significant association of $B C H E-K$ with Alzheimer type neuropathological changes in the ApoE $\varepsilon 4$ carriers older than 75 years, but not in the non-ApoE $\varepsilon 4$ carriers. Lehmann et al showed that $B C H E-K$ was strongly associated with the development of Alzheimer's disease in the ApoE \&4 carriers older than 75 years. ${ }^{1}$ Analyses of the same subgroup of ApoE $\varepsilon 4$ carriers older than 75 years increased statistical significance in both our studies and that of Lehmann et al. This suggests that $B C H E-K$ as a genetic marker is linked with formation of Alzheimer type neuropathological changes or development of Alzheimer's disease in the ApoE $\varepsilon 4$ carriers older than 75 years. However, a decrease of the severity of Alzheimer type neuropathological changes with $B C H E-K$ in our study was not expected because Lehmann et al showed an increase in frequency of the $B C H E-K$ allele in Alzheimer's disease. ${ }^{1}$ Singleton et al also reported that $B C H E-K$ was not associated with the densities of the SPs and NFTs, even in the ApoE $\varepsilon 4$ carriers. ${ }^{4}$ In addition, $B C H E-K$ was not related to the development of Alzheimer's disease in the ApoE $\varepsilon 4$ carriers in our study. Russ et $a l^{3}$ and Singleton et $a l^{4}$ also showed a lack of association between $B C H E-K$ and the development of Alzheimer's disease. However, Hiltunen et al showed that BCHE-K had a protective effect on the development of Alzheimer's disease in ApoE $\varepsilon 4$ carriers younger than 75 years. ${ }^{5}$ The effects of $B C H E-K$ on the Alzheimer type neuropathological changes or development of Alzheimer's disease are different among studies, suggesting that the significant genetic association in the studies by Lehmann et al, ${ }^{1}$ Hiltunen et $a l^{5}$ and ourselves might be linkage disequilibrium with relevant variability in $\mathrm{BCHE}$ or other adlacent gene on chromosome 3, and that $B C H E-K$ does not play a direct part in the pathogenesis of Alzheimer's disease.

BCHE genotypes and the densities of the SPs, NPs and NFTs in the hippocampus and superior temporal gyrus in ApoE 44 carriers older than 75 years and non-ApoE $\& 4$ carriers older than 75 years

\begin{tabular}{|c|c|c|c|c|c|c|c|}
\hline \multirow[b]{2}{*}{ BCHE genotype } & \multicolumn{3}{|c|}{ ApoE $\varepsilon 4$ carriers over 75 years $(n=28)$} & \multicolumn{4}{|c|}{ non- $A$ poE $\varepsilon 4$ carriers over 75 years $(n=95)$} \\
\hline & $K / N(n=8)$ & $N / N(n=20)$ & $p$ & $K / K(n=4)$ & $K / N(n=25)$ & $N / N(n=66)$ & $p$ \\
\hline \multicolumn{8}{|l|}{ Hippocampus: } \\
\hline SPs & $3.0(0.0,17.2)$ & $12.2(4.5,28.7)$ & 0.13 & $0.0(0.0,5.7)$ & $0.0(0.0,16.7)$ & $0.0(0.0,10.3)$ & 0.69 \\
\hline NPs & $0.7(0.0,11.9)$ & $11.0(3.9,25.3)$ & 0.07 & $0.0(0.0,3.5)$ & $0.0(0.0,14.0)$ & $0.0(0.0,8.6)$ & 0.63 \\
\hline NFTs & $1.1(0.4,23.1)$ & $17.4(2.5,59.6)$ & 0.12 & $3.9(0.9,10.0)$ & $7.0(0.6,35.7)$ & $4.6(0.4,15.0)$ & 0.72 \\
\hline \multicolumn{8}{|c|}{ Superior temporal gyrus: } \\
\hline SPs & $0.2(0.0,22.8)$ & $49.7(12.1,83.8)$ & 0.007 & $0.0(0.0,58.0)$ & $6.0(0.0,64.8)$ & $1.2(0.0,44.0)$ & 0.61 \\
\hline NPs & $0.2(0.0,8.8)$ & $10.7(3.6,19.0)$ & 0.02 & $0.0(0.0,3.7)$ & $2.0(0.0,6.5)$ & $0.4(0.0,7.8)$ & 0.59 \\
\hline NFTs & $0.0(0.0,0.2)$ & $0.9(0.0,4.9)$ & 0.04 & $0.0(0.0,0.0)$ & $0.0(0.0,0.5)$ & $0.0(0.0,0.4)$ & 0.32 \\
\hline
\end{tabular}

Values are medians (25th percentile, 75 th percentile). The density represents the average counts in $2.56 \mathrm{~mm}^{2}$ for the SPs and NPs, and in $0.64 \mathrm{~mm}{ }^{2}$ for the NFTs. $\mathrm{BCHE}=$ butyrylcholinesterase gene; ApoE=apolipoprotein $\mathrm{E} ; \mathrm{K}=$ the $\mathrm{K}$ variant allele of butyrylcholinesterase gene; $\mathrm{N}=$ the normal allele of butyrylcholinesterase gene; $\mathrm{SPs}=$ senile plaques; NPs=senile plaques with dystrophic neurites; NFTs=neurofibrillary tangles. 
We are grateful to I Isahai, $M$ Takeda, $\mathrm{H}$ Konuma, and Y Miura for their expert technical assistance. The study was supported in part by a Health Science Research Grant to MY from the Ministry of Health and Welfare, Japan and a Grant-in-Aid for Scientific Research to MY from the Ministry of Education, Science, Sports and Culture, Japan.

N SODEYAMA

$M$ YAMADA

H MIZUSAWA

Department of Neurology

Y ITOH

E OTOMO

Department of Internal Medicine, Tokyo Medical and Dental University, Tokyo, fapan

N SUEMATSU

Department of Pathology, Yokufukai Geriatric Hospital, Tokyo, fapan

M MATSUSHITA

Department of Neuropathology, Tokyo Institute of Psychiatry, Tokyo, fapan

Correspondence to: Dr Masahito Yamada, Department of Neurology, Tokyo Medical and Dental University, Yushima 1-5-45, Bunkyo-ku, Tokyo 113-8519, Japan. Telephone 008135803 5234; fax 008135803 0169; email m-amada.nuro@ med.tmd.ac.jp

1 Lehmann DJ, Johnston C, Smith AD. Synergy between the genes for butyrylcholinesterase $\mathrm{K}$ variant and apolipoprotein E4 in late-onse confirmed Alzheimer's disease. Hum Mol Genet 1997;6:1933-6.

2 Sodeyama N, Itoh $\mathrm{Y}$, Suematsu $\mathrm{N}$, et al. Presenilin 1 intronic polymorphism is not assocresen with itzheimo polymorphism is not associated with Alzheimer type neuropathological changes or sporadic Alzheimer's disease. F

3 Russ C, Powell J, Lovestone S, et al. K variant of Russ C, Powell J, Lovestone S, et al. K variant of
butyrylcholinesterase and late-onset butyrylcholinesterase and late-
Alzheimer's disease. Lancet 1998;351:881.

4 Singleton AB, Smith G, Gibson AM, et al. No association between the $K$ variant of the butyrylcholinesterase gene and pathologically confirmed Alzheimer's disease. Hum Mol Gene 1998;7:937-9.

5 Hiltunen M, Mannermaa A, Helisalmi S, et al. Butyrylcholinesterase $\mathrm{K}$ variant and apolipoprotein E4 genes do not act in synergy in Finnish late-onset Alzheimer's disease patients. Neurosci Lett 1998;250:69-71.

\section{Ideomotor prosodic apraxia}

Prosody is a non-verbal or suprasegmental feature of language that conveys various levels of information to the listener, including linguistic, affective (attitudinal and emotional), dialectical, and idiosyncratic data. The acoustical features underlying prosody include pitch, intonation, melody, cadence, loudness, timbre, tempo, stress, accent, and pauses. ${ }^{2}$ These acoustical features are typically spared in patients with cortical dementias such as Alzheimer's disease in which temporoparietal cortices are primarily affected. Patients with Alzheimer's disease, however, often develop apraxia, which can be defined as a disorder of skilled movement not caused by weakness, akinesia, deafferentation, abnormal tone or posture, movement disorders (such as tremor or chorea), intellectual deterioration, poor comprehension, or uncooperativeness. ${ }^{3}$ Moreover, subtypes of apraxia have been delineated and are defined by the nature of errors made by the patien and the means by which these errors are elicited. ${ }^{45}$ Accordingly, a patient with probable dementia of the Alzheimer's type is described who had normal prosodic elements to his spontaneous everyday speech, but could not produce the same acoustical features underlying prosody to command. The nature of his errors might constitute what can be termed "ideomotor prosodic apraxia."
The patient was a 71 year old, retired physician with a 3 to 4 year history of memory impairment. Neuropsychological evaluation disclosed a high average to superior general intellectual functioning, with mild impairment in naming to confrontation and episodic memory for visual and verbal memory. His visuospatial ability remained relatively unimpaired and was rated as average for his age. His comprehension for verbal and written instruction remained intact. At the present time he is still well oriented to time and place, and is somewhat independent in activities of daily living. $\mathrm{He}$ is, remarkably, not depressed, but does, repeatedly, raise concern regarding the "burden he has become to his wife." Moreover, mild hypoperfusion in the frontotemporal lobes bilaterally was seen on SPECT investigation and no evidence of pathognomonic laboratory results were found. Taken together, the pattern of episodic memory and naming impairments and functional imaging findings was thought to be consistent with the early stages of dementia of the Alzheimer's type (DAT) in keeping with National Institute of Neurological and Communicative Disorders Association-Alzheimer's Disease and Related Disorders Association criteria. ${ }^{6}$ The patient was consequently referred to our department for "prospective memory book training" and follow up assessments to index progression of disease.

During our sessions his wife had stated that the patient could no longer "act" and complained that her once "flamboyant" and "unblushing" husband could no longer "put any feeling into his lines" when they read play scripts together. She thought that he had "lost his enthusiasm to act" consequent to his new found memory loss and an "understandable depressive reaction." It became clear, however, that the patient was remarkably not depressed and that he maintained normal prosodic speech during conversation. When asked to use prosody to command when reading script, however, this once gallant actor spoke without melody, loudness, stress, nor accent, with inappropriate pauses. To quantify this patient's peculiar deficit, the patient was required to read and repeat words and sentences to prosodic command and imitation. Observation revealed five single words and five sentences that the patient often and spontaneously uttered with normal prosody, such as "Honey, PLEASE(!)." These 10 items were used to assess the patient's ability to produce prosody to command and imitation (table). For example, the patient was told to read the words

Ten item prosodic apraxia scale

\begin{tabular}{|c|c|}
\hline Script to be read & Type of emphasis \\
\hline 1. Honey PLEASE! & Accentuate PLEASE! \\
\hline 2. Are you hungry? & Rise in pitch \\
\hline $\begin{array}{l}\text { 3. You know.......there was a time when I could } \\
\text { recite all the streets in my neighborhood }\end{array}$ & Pause after "You know" \\
\hline 4. Holy COW! & With surprise \\
\hline 5. YUP, yup, yup, yup, yup... & $\begin{array}{l}\text { As if you were distressed with decenting } \\
\text { intonation and stress }\end{array}$ \\
\hline 6. La de da da... & With melody \\
\hline 7. O Canada, our home and native land... & With proper tempo, as if you were singing \\
\hline 8. SHIT! & As if you were frustrated and upset \\
\hline 9. Thank you & As if you sincerely meant it \\
\hline $\begin{array}{l}\text { 10. May I go to the bathroom, I really need to go } \\
\text { quite badly... }\end{array}$ & $\begin{array}{l}\text { As if you really meant it, accentuating the word } \\
\text { "REALLY" }\end{array}$ \\
\hline
\end{tabular}

Directions: Read the above word[s] and sentences as if you really mean them. Pretend you are auditioning for a play and you are required to read the lines with the type of emphasis noted beside each line.

*These items were selected based on observation of the patients spontaneous speech. Therefore, they are qualitatively constructed and should not be used as a general measure of prosodic apraxia with all patients.
"Honey PLEASE!" with loudness, stress, accentuation of the word "please," and as if he really meant it. If he failed (the words were read without the acoustical features exexperimenter's reading of the word(s) or sentence which incorporated the appropriate prosodic elements only after he was asked to describe the affective prosodic quality of the phrase to ensure good comprehension. Five age matched normal healthy controls volunteered to read the items found in the table, word or phrase with appropriate and the pected prosody.

The patient was unable to read any words or sentences with normal (appropriate and expected) prosody. Indeed, the patient had lost his ability to "act." The patient's use of prosody did, however, improve dramatically with imitation. That is, he was able to repeat eight of the 10 items in the table with appropriate and expected prosody. Interestingly, trouble producing was item three (You know ... there was a time when ...). He could not pause after the words "you know" suggesting that this patient seems to also have features characteristic of motor aprosodia. Hence, because he had available the knowledge to successfully select and use appropriate prosody, but failed to produce prosodic speech to command, dysfunction of the than the conceptual system. ${ }^{3}$ Thus, ideomotor prosodic apraxia can be defined as an inability to produce prosody to command during speech. The precise underlying mechanism(s)] responsible for producing this deficit is unknown, although Heilman et al and Tucker et $a l^{8}$ have hypothesised that the right hemisphere is indeed dominant for organising the affective-prosodic components the functional anatomical organisation of affective language in the right hemisphere was analogous to the organisation of propositional language in the left (non-dominant) hemisphere. Conceptually, therefore, evipoor affective prosody to command and good affective prosodic repetition and comprehension would suggest a "transcortical motor aprosodia." Note however, that the patient's spontaneous prosody was unaffected whereas spontaneous speech is affected by a transcortical motor aphasia. Hence, we might place the critical lesion for prosodic apraxia in the right dorsolateral frontal lobe, extending into the deep frontal pected), the patient was asked to imitate the 
white matter, in keeping with typical dominant hemispheric lesions producing transcortical motor aphasia. This speculation is supported by the patient's SPECT findings of mild hypoperfusion in the frontotemporal lobes bilaterally.

KONSTANTINE K ZAKZANIS Department of Psychology, Division of Life Sciences, University of Toronto, Canada

Correspondence to: Dr Konstantine K Zakzanis, Department of Psychology, Division of Life Sciences, University of Toronto, 1265 Military Trail, Toronto, Ontario, Canada M1C 1A4. email zakzanis@scar.utoronto.ca

1 Monrad-Krohn GH. The third element of speech: prosody and its disorders. In: Halpern L, ed. Problems in dynamic neurology. Jerusalem: Led. Problems in dynamic neurology. Jerusal

2 Ross E. The aprosodias. In: Feinberg TE, Farah MJ, eds. Behavioral neurology and neuropsychology. New York: McGraw-Hill, 1997:699-709.

3 Heilman KM, Rothi LJG. Apraxia. In: Heilman KM, Valenstein E, eds. Clinical neuropsychology. 3rd ed. New York: Oxford University Press, 1993.

4 Rothi LJG, Heilman KM. Apraxia: the neuropsychology of action. East Sussex, UK: Psychology Press, 1997.

5 Roy EA. Hand preference, manual asymmetries and limb apraxia. In: Elliot E, Roy EA, eds. Manual asymmetries in motor performance. Boca Raton: CRC Press, 1996:215-36.

6 McKhann G, Drachman D, Folstein M, et al. Clinical diagnosis of Alzheimer's disease: report of the NINCDS-ADRDA work group port of the NINCDS-ADRDA work group
under the auspices of the Department of Health and Human Services Task Force on Health and Human Services Task Force on
Alzheimer's disease, Neurology 1984;34:939-

7 Heilman KM, Bowers D, Speedie L, et al. Comprehension of affective and nonaffective speech. Neurology 1984;34:917-21.

8 Tucker DM, Watson RT, Heilman KM. Discrimination and evocation of affectively intoned speech in patients with right parietal disease. Neurology 1977;27:947-50.

Vocal cord abductor paralysis in spinocerebellar ataxia type 1

Vocal cord abductor paralysis (VCAP) is considered a sign of a poor prognosis in neurodegenerative diseases, because severe laryngeal dysfunction by VCAP may result in acute airway obstruction and require emergency tracheotomy. ${ }^{1}$

Although VCAP is a cardinal feature in multiple system atrophy (MSA), it has not been reported in several types of spinocerebellar ataxia with dominant inheritance. We evaluated the movements of the vocal cords of seven patients with SCA1 by laryngofibroscopy.

Seven unrelated patients with SCA1 who had the expanded CAG repeat of ataxin-1 were investigated. There were two men and five women ranging in age from 27 to 67 years old (mean 44.5 years). Spouses and other family members, in addition to the patients, were questioned about events of stridor, dyspnoea, and dysphagia. Vocal cord movement was examined by laryngofibroscopy and recorded during inspiration and phonation.
The rating scale used to evaluate maximal abduction of the vocal cords during larygofibroscopy was as follows: $(-)=$ normal; $(+)=$ median position; $(++)=$ paramidline position; $(+++)=$ midline position. For the evaluation of VCAP, we tried the respiratory flow volume loop study as well in one patient (patient 2) in whom maximal abduction of the vocal cords was slightly limited $(+)$ on laryngofibroscopy.

The correlations between VCAP and CAG repeat length or duration of illness were analysed with the non-parametric MannWhitney $U$ test.

The clinical features, including the vocal cord findings, are summarised in the table. VCAP was present in five of the seven patients with SCA1. Although it is difficult to know when the VCAP first became manifest in each patient, patient 1 showed VCAP confirmed by laryngofibroscopy only 2 years after the onset of gait disturbance.

All five patients with VCAP showed mild dysphagia requiring no tube feeding, and four patients had a history of stridor at night. Patient 1 showed VCAP accompanying dysphagia without stridor at night even in an early stage of the disease. The VCAP was found to be severe on laryngofibroscopy in all three patients with breathing difficulty on inspiration. Patient 5, who had the severest VCAP, developed stridor during wakefulness as well. In patients 4 and 5, the breathing difficulty on inspiration was improved by tracheostomy. The respiratory flow volume loop study did not detect abnormality in patient 2 .

The CAG repeat number tended to be higher in the patients with VCAP than in the patients without VCAP $(p=0.05)$, but the duration of illness was not significantly correlated with the presence of VCAP $(\mathrm{p}=0.43)$.

This is the first report that VCAP is often found in patients with SCA1. As VCAP may not usually be a late feature in patients with SCA1, evaluation of VCAP is necessary even in early stages of the disease. It is not surprising to find VCAP in patients with stridor, because stridor is usually caused by airway obstruction of the larynx. However, VCAP was detected by laryngofibroscopy in a patient without stridor who had dysphagia. Furthermore, all patients with VCAP exhibited dysphagia. We therefore think that laryngofibroscopy should be performed in SCA1 patients with dysphagia as well as stridor.

The mechanism of VCAP may be divided into some types, the paralytic type, the nonparalytic type, and these two combined type. ${ }^{2}$ The first is possibly caused by loss of neurons in the nucleus ambiguus. ${ }^{23}$ The second is considered to be due to overactivity of the intrinsic laryngeal muscles. ${ }^{2}$ Stridor due to paralysis has been found to be more prominent in sleep than during wakefulness; whereas stridor by non-paralytic dysfunction has been found both during the daytime and during sleep. ${ }^{2}$ We suspect that the VCAP in patients with SCA1 may be dominantly paralytic, because the nucleus ambiguus is sometimes pathologically involved in SCA1 and because stridor in our patients with SCA1 was more marked in sleep. ${ }^{5}$

Our laryngofibroscopic findings suggested that severe VCAP caused breathing difficulty on inspiration in the patients with SCA1 by obstructing the airway. Moreover, the stridor during wakefulness as well as sleep indicated it to be very serious. The important question concerns when tracheostomy should be carried out after the diagnosis of VCAP to prevent respiratory abnormalities leading to sudden death. Although we consider tracheostomy at the stage when breathing difficulty on inspiration or stridor during wakefulness is noted, it awaits further study with a large number of patients to decide which stage is best for tracheostomy.

Furthermore, we now consider endoscopic cord lateralisation as another possible management for VCAP.

$$
\begin{array}{r}
\text { T SHIOJIRI } \\
\text { T TSUNEMI } \\
\text { T MATSUNAGA } \\
\text { Department of Neurology, Asahi General Hospital, } \\
\text { Chiba, fapan } \\
\text { H SASAKI } \\
\text { I YABE } \\
\text { K TASHIRO } \\
\text { N NISHIZAWA } \\
\text { Department of Neurology } \\
\text { Department of Oto-Rhino-Laryngology, Hokkaido } \\
\text { University School of Medicine, Hokkaido, Fapan } \\
\text { K TAKAMOTO } \\
\text { Department of Neurology, Tokyo Metropolitan } \\
\text { Neurological Hospital, Tokyo, Fapan } \\
\text { T YOKOTA } \\
\text { H MIZUSAWA }
\end{array}
$$

Tokyo Medical and Dental University, Tokyo, fapan Correspondence to: Dr Toshiaki Shiojiri, Department of Neurology, Asahi General Hospital, I-1345, Asahi-city, Chiba 289-2511, Japan. Telephone 0081 47963 8111; fax 0081479601210 .

1 Williams A, Hanson D, Calne DB. Vocal cord paralysis in the Shy-Drager syndrome. 7 Neurol Neurosurg Psychiatry 1979;42:151-3.

2 Isozaki E, Shimizu T, Takamoto K, et al. Vocal cord abductor paralysis (VCAP) in Parkinson's disease: difference from VCAP in multiple sys-

\begin{tabular}{|c|c|c|c|c|c|c|c|c|c|c|}
\hline Patient & Age/sex & Onset (y) & $\begin{array}{l}\text { Disease } \\
\text { duration (y) }\end{array}$ & $\begin{array}{l}\text { Vocal cord } \\
\text { paralysis }\end{array}$ & $\begin{array}{l}\text { Stridor at } \\
\text { night }\end{array}$ & $\begin{array}{l}\text { Stridor during } \\
\text { wakefulness }\end{array}$ & Dysphagia & $\begin{array}{l}\text { Breathing } \\
\text { difficulty }\end{array}$ & Tracheotomy & $\begin{array}{l}(C A G) n \text { of } \\
\text { mutant allele }\end{array}$ \\
\hline 1 & $30 / \mathrm{M}$ & 28 & 2 & + & - & - & + & - & - & 53 \\
\hline 2 & $48 / \mathrm{F}$ & 39 & 9 & + & + & - & + & - & - & 48 \\
\hline 3 & $27 / \mathrm{F}$ & 20 & 7 & ++ & + & - & + & + & - & 59 \\
\hline 4 & $34 / \mathrm{M}$ & 23 & 11 & ++ & + & - & + & + & + & 52 \\
\hline 5 & $56 / \mathrm{F}$ & 46 & 9 & +++ & + & + & + & + & + & 47 \\
\hline 6 & $67 / \mathrm{F}$ & 51 & 14 & - & + & - & + & - & - & 46 \\
\hline 7 & $50 / \mathrm{F}$ & 41 & 8 & - & - & - & - & - & - & 46 \\
\hline
\end{tabular}

tem atrophy. Neurol Sci 1995;130:197-202.

Hayashi M, Isozaki $M$, Oda $M$, et al. Loss of large myelinated nerve fibers of the recurrent laryngeal nerve in patients with multiple system atrophy and vocal cord palsy. 7 Neurol Neurosurg Psychiatry 1997;62:234-8.

4 Isozaki E, Naito A, Horiguchi S, et al. Early diagnosis and stage classification of vocal cord abductor paralysis in patients with multiple system atrophy. $\mathcal{F}$ Neurol Neurosurg Psychiatry 1996;60:399-402.

5 Genis D, Matilla T, Volpini V, et al. Clinical, neuropathologic and genetic studies of a large spinocerebellar ataxia type 1 (SCA1) kindred: (CAG) n expansion and early premonitory signs and symptoms. Neurology 1995;45:24-30.

Brief summary of the clinical features and CAG repeat numbers in the patients with SCA1

$\star(-)=$ normal,$(+)=$ median position, $(++)=$ paramidline position, $(+++)=$ midline position. 
Lateral gaze synkinesis on downward saccade attempts with paramedian thalamic and midbrain infarct

The symptoms of paramedian thalamic and midbrain infarct include ocular motor disturbances mainly in the vertical plane. ${ }^{1}$ We here describe a patient with the additional feature of an unusual horizontal eye movement synkinesis.

A 60 year old overweight man, with diabetes and mild hypertension, suddenly fell into a coma that lasted for 4 hours and was followed by slight right hemiparesis, recent memory impairment, hypersomnia, and vertical gaze impairment.

On admission to our centre, about 10 days after symptom onset, the patient still presented fluctuating drowsiness from which he could be easily aroused, normal cognitive functions with mild attention disturbance, slight right facial weakness, and mild incoordination at the finger-to-nose test with his right arm.

The most important findings involved ocular motor function. Both pupils were normal in diameter and reacted normally both to light and to convergence. The cover test did not disclose any eye misalignment. During attempted fixation, the patient

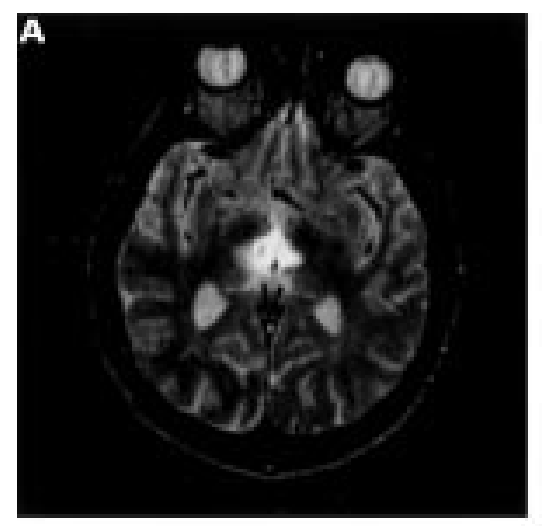

showed saccade oscillations (usually square and macrosquare wave jerks) - that is, back to back involuntary horizontal saccades with an amplitude ranging from about 2 to about 10 degrees and with an intersaccadic interval of about $200 \mathrm{~ms}$, that brought the eyes away from and back to the fixation point, at an approximate rate of three every 2 seconds. Clinical examination of eye movements in the horizontal plane and visually guided reflexive saccades recorded by the infrared reflection technique were both normal, whereas the amplitude range of vertical saccade and smooth pursuit eye movements covered only a few degrees of upward gaze. Vertical amplitude range was slightly greater for the vestibulo-ocular reflex in the pitch (yes-yes) plane. Moreover, when the patient attempted to make a downward saccade, he showed a gaze deviation to the left (figure). This synkinesis was more evident when the examiner lifted the patient's lids, thus preventing lid synkinesis during downgaze. Attempted upward saccades did not produce any horizontal gaze deviation. Finally, the patient showed normal Bell's phenomenon.

An EEG showed frontal, bilateral theta and theta/delta activity and sporadic drowsiness, and MRI (figure) disclosed

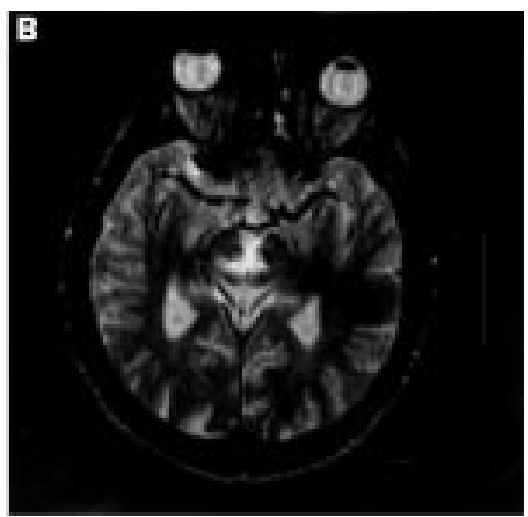

C

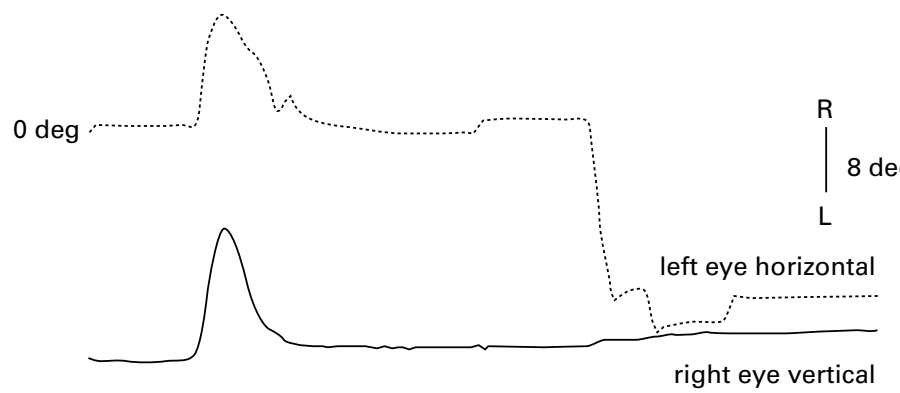

$0.5 \mathrm{~s}$

(A) and (B) show a thalamomesencephalic ischaemic lesion, hyperintense in T2 weighted scans (SE, TR=2300 ms; TE=25 ms). The lesion involves the anteromedial portion of both thalami, but the right one to a larger exrtent. In the midbrain, the lesion is located around the Sylvian acqueduct, and symmetrically, but prevalently right sided, and involves the area that is located posteromedially with respect to both red nuclei. (C) Recording of the horizontal (upper tracing) and of the vertical (bottom tracing) movement recorded respectively from the left and right eye with the infrared reflection technique (Skalar, IRIS system) during an attempted downward saccade. The vertical tracing is flat, as the patient was unable to move his eyes downward. By contrast, the horizontal tracing shows a concomitant leftward saccade. At outset, both tracings show a blink artifact. a bilateral thalamomesencephalic infarct which involved predominantly the right side.

Horizontal gaze deviation on attempted downward saccades disappeared after about 15 days, whereas vertical gaze impairment and hypersomnia were unchanged 1 year later. Subsequent polisomnographic testing disclosed sleep apnoea.

The clinical features of our patient are those reported for thalamic infarct involving the rostrointerstitial nucleus of the medial longitudinal fasciculus (riMLF). By contrast, the leftward gaze deviation elicited by the attempt to make a downward saccade is at variance with all previous descriptions.

The triggering of a saccade requires not only the activation of the exitatory burst neurons (EBNs), but also the deactivation of the omnipause neurons (OPNs), which provide tonic inhibition of both horizontal and vertical EBNs.

Accordingly, any attempt to activate a lesioned riMLF should be associated with maximal OPN inhibition. However, OPNs discharge for saccade in any direction and are not strictly direction selective, ${ }^{2}$ as shown by horizontal oscillations during vertical saccades detectable in normal subjects. ${ }^{3}$ These oscillations suggest that during vertical saccades the inhibition of OPNs disinhibits both vertical and, to a lesser extent, horizontal EBNs.

In our patient, the horizontal gaze deviation was always directed to the left rather than in both directions as during oscillations. Many ocular motor structures, including those located in the midbrain, ${ }^{4}$ trigger a purely vertical (downward) saccade only when stimulated bilaterally, so as to nullify horizontal components with different direction depending on the stimulation side. This probably occurs for the riMLF too, as it shows ipsilateral projections to the abducens nucleus. ${ }^{5}$ In our patient, the projections to the left nucleus were probably spared by the fact that the lesion predominantly affected the right side.

Overall, our patient's horizontal ocular motor synkinesis is unusual, and probably derives from a strong inhibition of OPNs, which in turn frees the horizontal EBNs, and from an unbalanced activation of the left abducens neurons via riMLF projections spared from the lesion, although it is not possible to exclude the possibility that the unbalanced activation of abducens neurons originated from frontal or parietal cortical areas or from the superior colliculus rather than from riMLF projections.

This hypothesis is strengthened by the reinforcement of the leftward eye deviation when the examiner kept the patient's lids lifted. Since this manoeuvre prevents lid synkinesis, it results in what resembles an attempted forced lid closure which, on the basis of blink induced eye oscillations, ${ }^{6}$ is likely to be an additional stimulus for OPN inhibition. Moreover, although they occur in various conditions, saccade oscillations during fixation are in keeping with a reduction of OPN inhibition level.

In conclusion, our patient presented an ocular motor synkinesis that should be listed among those occurring in thalamomesencephalic infarcts. This sign is unusual and it is likely to be overlooked, but it is fully explicable both by neurophysiology and 
by anatomical connections of the saccade system.

M VERSINO

F SIMONETTI

M G EGITTO

$M$ CERONI

V COSI

Fondazione IRCCS Istituto Neurologico C Mondino,

M VERSINO

M CERONI

$\mathrm{V}$ COSI

Dipartimento Scienze Neurologiche

G BELTRAMI

Dipartimento di Informatica e Sistemistica,

Università di Pavia, Italy

Correspondence to: Dr Maurizio Versino, Dipartimento Scienze Neurologiche, Università di Pavia, Fondazione Istituto Neurologico C Mondino IRCCS, Via Palestro 3, 27100 Pavia, Italy. Telephone 00390382 380340; fax 00390382 380286; email mversino@unipv.it

1 Castaigne P, Lhermitte F, Buge A, et al. Paramedian thalamic and midbrain infarcts: clinical and neuropathological study. Ann Neurol 1981;10:127-48.

2 Nakao S, Shiraishi Y, Li W, et al. Cat pontine omnipause neurons: direct inhibitory connecing in the genesis of vertical saccades. Acta Otolaryngol 1991;481(suppl): 199-204.

3 Zee DS, Fitzgibbon EJ, Optican LM. Saccadevergence interactions in humans. F Neurophysio 1992;68:1624-41.

4 Kömpf D, Pasik T, Pasik P, et al. Downward gaze in monkeys. Stimulation and lesion studies. Brain 1979;102:527-58.

5 Langer T, Kaneko CRS, Scudder CA, et al. Afferents to the abducens nucleus in the monkey and cat. F Comp Neurol 1986;245:379-400.

6 Hain TC, Zee DS, Mordes M. Blink-induced saccadic oscillations. Ann Neurol 1986;19:299301

7 Averbuch-Heller L, Kori AA, Rottach KG, et al. Dysfunction of pontine omnipause neurons causes impaired fixation: macrosaccadic oscillations with unilateral pontine lesion. Neuroophthalmology 1996;16:99-206.

\section{Botulinum toxin is a useful treatment in excessive drooling of saliva}

Excessive drooling of saliva or hypersialorrhea is a common problem in neurodegenerative disorders such as motor neuron disease or Parkinson's disease. It is usually caused by swallowing dysfunction and can facilitate choking, aspiration, and chest infections. Socially it is embarrassing and disabling. There are not many treatment options. Anticholinergic drugs are sometimes tried but are usually of little benefit and side effects (orthostatic hypotension, dizziness, and mental confusion, particularly in the elderly) limit their usefulness.

Occasionally, as a more drastic treatment irradiation of the parotid gland is carried out when hypersialorrhea becomes intractable.

Apart from its established usefulness in dystonia, spasticity and strabismus there are some data showing that botulinum toxin injections are effective in autonomic disorders - for example, gustatory sweating and hyperhidrosis of the palm. ${ }^{2}$ It has been hypothesised that botulinum toxin may help in sialorrhea. ${ }^{3}$ In a historical note Erbguth recently pointed out the potential use of botulinum toxin for hypersalivation, quoting a paper by the German physician and poet Justinus Kerner written in $1817 .{ }^{4}$

Botulinum toxin inhibits acetylcholine release in nerve terminals mainly at the neuromuscular junction, but also in sympathetic and parasympathetic ganglion cells and in postganglionic parasympathetic nerves, by blocking SNAP-25, a protein involved in the fusion of acetylcholine containing vesicles with the plasma membrane. ${ }^{5}$

Against this background we evaluated the usefulness of botulinum toxin injections into the parotid gland in four patients with excessive drooling of saliva, with their consent. One patient had young onset secondary generalised dystonia with severe mouth opening spasms, one had advanced Parkinson's disease, the third patient had progressive supranuclear palsy, and the fourth patient had motor neuron disease. Drooling in these patients was so severe that they had to wear a bib or carry a towel around their neck. With one exception 20 units of Dysport( (Ipsen) were injected superficially subcutaneously above the angle of the mandible at the posterior margin of the masseter muscle, avoiding the bulk of the muscle. The shorter version $(5 / 8$ ") of the 25 gauge needle was used. Because worsening of dysphagia was feared only $10 \mathrm{U}$ Dysport were injected into each parotid gland in the patient with motor neuron disease. Drooling did not significantly improve in this patient, possibly due to the low dose of botulinum toxin used. He declined further treatment.

All the other patients had a beneficial response beginning by the end of the first week and lasting 6 weeks in one patient and 3 to 4 months in the others. Apart from subjective improvement reported by the patients and caregivers, reduction of drooling was demonstrated by the fact that the patients did not have to use a bib or towel. One patient had mild worsening of existing dysphagia. Two patients had mild chewing difficulties, possibly due to diffusion of the toxin into the masseter and one patient complained of a dry mouth. None developed facial weakness. All three patients considered the response good enough and side effects sufficiently minimal for them to continue botulinum toxin treatment at regular intervals.

Injections of botulinum toxin into the parotid gland (and other salivary glands) may be an effective and simple treatment for excessive disabling drooling of saliva in selected patients.

AM was supported by the Ernst Jung-Stiftung für Wissenschaft und Forschung in Hamburg, Germany.

KP BHATIA

A MÜNCHAU BROWN

Institute of Neurology, Queen Square,

London, UK

Correspondence to: Dr Kailash P Bhatia, University Department of Clinical Neurology, Institute of Neurology, Queen Square, London WC1N 3BG, UK. Tel 00441718373611 extention 4228; fax $0044 \quad 171278$ 5616; email HYPERLINK mailto:K.Bhatia@ion.ucl.ac.uk

1 Naumann M, Zellner M, Toyka KV, et al. Treatment of gustatory sweating with botulinum toxin. Ann Neurol 1997;42:973-5.

2 Schnider P, Binder M, Auff E, et al. Doubleblind trial of botulinum A toxin for the treatment of focal hyperhidrosis of the palms. Br ₹ Dermatol 1997;136:548-52.

3 Bushara KO. Sialorrhea in amyotrophic lateral sclerosis: a hypothesis of a new treatment: sclerosis: a hypothesis of a new treatment: botulinum toxin A injections of the par

4 Erbguth FJ. Botulinum toxin, a historical note. Lancet 1998;351:1820.

Lancet 1998;351:1820.
Blasi J, Chapman ER, Link E, et al. Botulinum

Blasi J, Chapman ER, Link E, et al. Botulinum
toxin selectively cleaves the synaptic protein toxin selectively cleaves the synapt
SNAP-25. Nature 1993;365:160-3.

Extensive brain calcifications systemic sclerosis: two cases
Systemic sclerosis (scleroderma) is a multisystem connective tissue disease of unknown aetiology, characterised by progressive fibrosis of the skin and internal organs including the lungs and gastrointestinal tract. ${ }^{1}$ Pathological calcification of soft tissues (known as calcinosis) is a common feature in the CREST syndrome of scleroderma (calcinosis, Raynaud's phenomenon, oesophageal dysmotility, sclerodactyly, telangiectasia). By contrast, internal organ calcification is rare, and isolated cases of spinal calcinosis and calcific constrictive pericarditis have been reported. ${ }^{2}$ We report here the cases of two patients with systemic sclerosis whose CT examination disclosed extensive brain calcifications.

Case 1, a 48 year old man was referred to hospital because of polyarthralgia involving the wrists and ankles, Raynaud's phenomenon, and tightness of hand skin. The patient's wife had noticed that during the previous months, he had a slowed mentation and a depressive mood. Physical examination disclosed a sclerodactyly but no telangiectasias. Routine haematological tests were normal. Antinuclear antibodies were positive at a $1 / 2000$ dilution with nucleolar fluorescence. Rheumatoid factors, antidouble stranded DNA and antiphospholipid antibodies were negative. There was no cryoglobulinaemia. Complement was normal. Lung function tests showed a restrictive syndrome (forced vital capacity $=75 \%$ predicted). Chest radiography was normal, as were oesophageal manometry and cardiac ultrasonographic examination. A diagnosis of systemic sclerosis was made and the patient was given diltiazem (180 mg/day) and ketoprofene (150 mg/day).

Six months later the patient's neurological status had worsened. He complained of memory loss, poor concentration, and insomnia. On neurological examination he was anxious and very slow in answering questions. Mini mental state examination score was $22 / 30$. The patient was oriented to place, but not to time. Anterograde amnesia was noted. Agnosia, apraxia, and aphasia were absent. There was no muscle weakness and muscle tone was normal, as were tendon reflexes. Plantar responses were both flexor. There was no sensory loss or impairment of cranial nerves. Systemic sclerosis signs were unchanged. Routine hematological tests were normal. Results of blood chemical tests were also unremarkable (serum electrolytes, urea, creatinine, iron), including phosphorus and calcium metabolism (serum parathyroid hormone concentration, blood calcium and phosphorus, 25-hydroxyvitamin D, 1,25dihydroxyvitamin $\mathrm{D}$, calciuria, and phosphaturia). Serum concentrations of free triodothyroxine, free thyroxine, and thyroid stimulating hormone were normal. Serological tests for syphilis, HIV-1,2, and Lyme disease were negative. Brain CT showed bilateral extensive calcification in the dentate nuclei (figure 1A), basal ganglia, and subcortical white matter (figure 1B). On MRI T1 weighted images and T2 weighted images, calcification was visible as a low intensity signal. The patient was given fluoxetine (20 $\mathrm{mg} /$ day) and bromazepam ( $6 \mathrm{mg} /$ day). At follow up, 1 year later, the patient's clinical status was unchanged, as was brain CT.

Case 2, a 64 year old right handed woman was admitted to hospital for evaluation of a Raynaud's phenomenon which had lasted for more than 10 years. At physical examination, sclerodactyly and tightness of the facial skin 


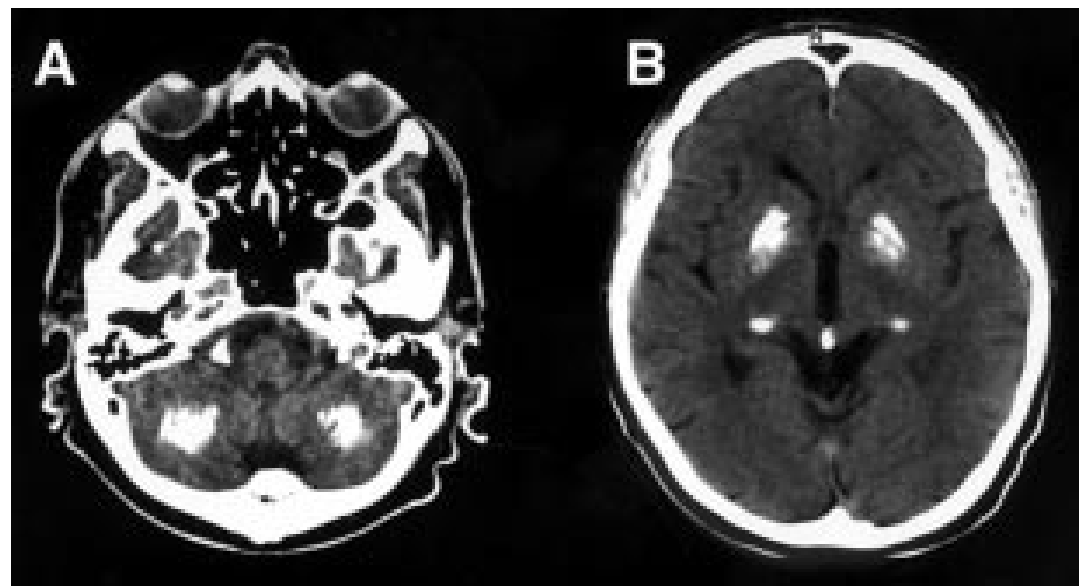

Brain CT of case 1 shows dense symmetric calcifications in the dentate nuclei (1A) and basal ganglia (1B).

were noted. Telangiectasias were present on the face, hands, and palate. The patient complained of pyrosis. Oesophageal manometry showed abnormalities of oesophageal motility. Hand radiography disclosed soft tissue calcifications. Anticentromere antibodies were positive at a 1/1000 dilution. A CREST syndrome was diagnosed and the patient was given buflomedil (600 mg/day) and prednisone ( $25 \mathrm{mg} /$ day).

One year later she was admitted for the evaluation of recent transient ischaemic attacks (TIAs). During the previous week she had experienced three bouts of expressive aphasia and right hemiplegia, each lasting about 10 minutes. She never smoked and did not have diabetes, hypertension, or dyslipidaemia. The neurological examination was normal. Routine blood chemical tests were normal (serum electrolytes, urea, creatinine) including phosphorus and calcium metabolism (serum parathyroid hormone concentration, blood calcium and phosphorus, 25hydroxyvitamin $\mathrm{D}, 1,25$-dihydroxyvitamin $\mathrm{D}$, calciuria, and phosphaturia). Cranial CT showed bilateral calcifications of the basa ganglia, and faint calcifications of the dentate nuclei and rubrum nucleus. Moderate cerebral and cerebellar atrophy was noted. Duplex carotid ultrasound and 24 hour ECG recording were normal. Echocardiography showed a normal left ventricle with an ejection fraction of $60 \%$. There was mild calcification and a thickening of the mitral valve leaflets. Aspirin (250 mg daily) was given at hospital discharge. No further TIA occurred during a 5 year follow up and the patient's clinical status has remained unchanged.

Systemic sclerosis is a multisystem disease predominantly affecting the skin, lungs, vascular system, and gastrointestinal tract. ${ }^{1}$ Neurological involvement occurs in a few patients (ranging from 0.8 to $18.5 \%$ ) including cranial nerve abnormalities, peripheral neuropathy, CNS vasculitis, and autonomic peripheral neuropathy. To our knowledge, extensive cerebral calcifications have not yet been reported.

Calcification of the brain is discovered in 0.8 to $1.2 \%$ of subjects undergoing routine CT examination, mainly in the globus pallidus. In most cases the deposits are small and involve older patients who remain asymptomatic, leading to the concept of "physiological" senescent basal ganglia calcifications. ${ }^{4}$ On the other hand, basal ganglia calcifications, often associated with dentate nuclei calcifications, have been reported in more than 30 conditions, including abnormalities of calcium phosphorus metabolism such as pseudohypoparathyroidism.

Systemic sclerosis leads to the formation of calcium deposits in the subcutaneous tissue. Rarely, the calcific process has been shown to involve the spine or pericardium. ${ }^{23}$ Recently, Heron et al described two cases of cerebral involvement in systemic sclerosis. ${ }^{6}$ In both cases necropsy showed extensive wall calcification of the small arteries and arterioles of the brain. Our two patients have scleroderma and extensive striopallidodentate calcifications and metabolic investigations failed to disclose any specific aetiology in either case. We think that scleroderma should be added to the list of conditions described as occurring with basal ganglia calcification.

The pathogenesis of the formation of calcium deposits in systemic diseases remains poorly understood. However, pathological calcification can be subdivided into metastatic (occurring in undamaged tissues when extracellular calcium and phosphate concentrations are increased) and dystrophic (ocurring in injured tissue when extracellular calcium and phosphate concentrations are normal) calcification. ${ }^{7}$ In our patients, as in the patients of Heron et al, the brain calcifying process may be related to primary cerebrovascular changes induced by systemic sclerosis.

Routine brain CT examination in systemic sclerosis could help to determine the true incidence of basal ganglia calcifications and their clinical relevance.

PATRICK BLANCO JEAN-FRANCOIS VIALLARD EMMANUEL ELLIE ISABELLE FAURE PATRICK MERCIÉ JEAN-LUC PELLEGRIN BERNARD LENG

Clinique de Médecine Interne, Hôpital Haut-Lévêque, avenue de Magellan, 33604 Pessac, France

Correspondence to: Dr Jean-François Viallard, Clinique de Médecine Interne, Hôpital HautLévêque, Centre François Magendie, 33604 Pessac, France. Telephone 0033 556556483; fax 0033 556556484.

1 Seibold JR. Scleroderma. In: Kelley WN, Harris ED, Ruddy S, et al, eds. Textbook of Rheumatology. Philadelphia: WB Saunders 1997:113362.

2 Ward M, Curé J, Schabel S, et al. Symptomatic spinal calcinosis in systemic sclerosis (sclerospinal calcinosis in systemic sclerosis (scler
derma). Arthritis Rheum 1997;40:1892-5.

3 Panchal P, Adams E, Hsieh A. Calcific constrictive pericarditis. A rare complication of
CREST syndrome. Arthritis Rheum 1996;39: 347-50.

4 Harrington MG, Macpherson P, McIntosh WB, et al. The significance of the incidental finding of basal ganglia calcification on computed tomography. I Neurol Neurosurg Psychiatry $1981 ; 44: 1168-70$

5 Ellie E, Julien J, Ferrer X, et al. Extensive cerebral calcification and retinal changes in pseudohypoparathyroidism. I Neurol 1989;236: 432-4.

6 Heron E, Fornes P, Rance A, et al. Brain involvement in scleroderma: two autopsy cases. Stroke 1998;29:719-21.

7 Anderson HC. Calcific lesions: a concept. Arch Pathol Lab Med 1983;107:341-8.

\section{CORRESPONDENCE}

All tibial foot: an electrophysiological artifact

Yamashita et $a l^{1}$ claim they have proved an "all tibial foot" for the motor innervation, an anomalous dual innervation of the tibialis anterior muscle by the deep peroneal and posterior tibial nerve, and a sensory coinnervation of the skin between the first and second toes by the tibial and deep peroneal nerve in a patient. To support their view they quote the letters of Linden and Berlit ${ }^{2}$ and of Glocker $e t a l,{ }^{3}$ ignoring our letter ${ }^{4}$ and that of Magistris and Truffert ${ }^{5}$, both considering the conclusions of Linden and Berlit and Glocker et al to be wrong. I point out that the mentioned letter of Linden and Berlit ${ }^{2}$ and our response to it were published in the same issue.

We have recorded a compound muscle action potential (CMAP) with a negative initial deflection on tibial nerve stimulation in $83 \%$ of 50 subjects, using a surface electrode over the extensor digitorum brevis. ${ }^{4}$ In the same subjects no potential was recorded by means of a concentric needle electrode inserted in the extensor digitorum brevis. ${ }^{1}$ In our view, this proves that the CMAP recorded by surface electrode over the extensor digitorum brevis on tibial nerve stimulation is a remote potential originated in the plantar muscles (volume conducted potential). Furthermore, we consider that the CMAP recorded over the tibialis anterior muscle by surface electrode on tibial nerve stimulation in the popliteal fossa, as reported by Yamashita et al, ${ }^{1}$ represents a volume conduction potential originating in the foot and toe flexors. The sensory nerve action potential recorded dorsally in the space between the first and the second toes on tibial nerve stimulation could also be a volume conducted potential originating in the first common plantar digital nerve, as the distance between this nerve and the recording electrode is short. Such volume conduction phenomena are known to occur on surface recordings from the median nerve at the wrist in severe carpal tunnel syndrome, when the forth finger is stimulated. It is unclear why Yamashita et al could not record a CMAP over the extensor digitorum brevis bilaterally on deep peroneal nerve stimulation in their young patient who did not have neuropathy. A probable explanation is a bilateral aplasia of the extensor digitorum brevis, comparable with the known aplasia of the thenar. ${ }^{6}$ The 
appropriate examination would have been a needle EMG of the extensor digitorum brevis.

GEORGIOS AMOIRIDIS

Department of Neurology, University of Crete, PO Box 1393, 71110 Heraklion, Crete, Greece. Telephone 003081 394651; email GAmoiridis@compuserve.com

1 Yamashita M, Mezaki T, Yamamoto T. "All tibial foot" with sensory crossover innervation Neurol Neurosurg Psychiatry 1998;65:798-9.
Netween the tibial and deep peroneal nerves.

2 Linden D, Berlit P. The intrinsic foot muscles Linden $\mathrm{D}$, Berlit $\mathrm{P}$. The intrinsic foot muscles are purely innervated by the tibial nerve (all
tibial foot): an unusual innervation anomaly. tibial foot): an unusual innerv
Muscle Nerve 1994;5:560-1.

3 Glocker FX, Deuschl G, Lucking CH. Traumatic lesion of the common peroneal nerve with complete foot drop and preserved dorsiflexion of the toes: an innervation anomaly. Muscle Nerve 1995;8:926-7.

4 Amoiridis G, Schols L, Meves S, et al. Fact and fallacy in clinical and electrophysiologica studies of anomalous innervation of the intrinsic foot muscles. Muscle Nerve 1996;9:1227-9.

5 Magistris MR, Truffert A. Extensor digitorum brevis innervated by the tibial nerve (all tibial foot): anomalous innervation or technical foot): anomalous innervation or
pitfall? Muscle Nerve 1997; 7:906-8.

6 Iyer KM, Stanley JK. Congenital absence of flexor pollicis brevis and abductor pollicis flexor pollicis brevis and
brevis. Hand 1982;3:313-6.

\section{BOOK REVIEWS}

Assessment Scales in Old Age Psychiatry. by ALISTAIR BURNS, BRIAN LAWLOR, and SARAH CRAig. (Pp 302, £29.95). Published by Martin Dunitz, London, 1999. IBSN 1-85317-562-5.

If it moves - measure it. Such is the trend in psychiatry and this has led to a proliferation of assessment scales of variable utility; from the esoteric to the ubiquitous. This book has them all and is, quite genuinely, one of the most useful volumes I have seen for a very long time. It covers everything from the AMTS through the MMSE to the KEW cognitive test. Each scale is presented in full together with a short commentary, critical references and, usefully, an estimated time taken to perform the test together with an address to contact the original author.

The scales presented are divided into those covering depression, neuropsychiatric assessments, activities of daily living, global assessments, visible assessments, delirium, caregiver assessments and scales for memory function. This organisation, together with a useful and functional index, will make the task of selecting an appropriate scale much easier in the future. Some of these scales are covered by patent law and my only quibble is that it would have been useful to know which instruments can be reproduced and for what purpose without fear of being billed for the privilege. Maybe highlighting such information would give unpatented authors a stimulus to visit their lawyer and therefore increase this deplorable practice.

This aside, I cannot recommend this book highly enough. By contrast with books that come highly recommended in diverse reviews but remain pristine on your library shelf, if you are ever fortunate enough to get hold of this volume from your institution library then you will, I guarantee, find it well thumbed. For academics, the book is a prayer answered and will become an essential resource in the planning and execution of any clinical research. For clinicians, psychologists, occupational therapists, and other members of the multidisciplinary old age psychiatry team, the collection of so many scales covering all aspects of mental health of elderly people should encourage the use of valid and reliable assessment procedures that enhance rather than detract from good clinical practice. My only question is "Why didn't somebody do this before".

\section{SIMON LOVESTONE}

Lumbar Disc Herniation. By FRANCO POSTACCHINI. (Pp 623, US\$299.00). Published by Springer-Verlag, Wien, 1999. ISBN 3-211-83118-5.

Professor Franco Postacchini is an orthopaedic surgeon at the University "La Sapienza" in Rome and is a well known widely respected spinal surgeon. He is to be congratulated on the production of this book which is wide ranging, comprehensive, and beautifully illustrated. The management of lumbar disc disease is fraught with uncertainty and there are many diagnostic and therapeutic pitfalls. The author has succeeded in addressing most of these controversies in a clear and logical fashion. He occasionally blurs the distinction between theories and established scientific fact forgetting that the practice of medicine and in particular the management of spinal disorders is full of paradoxes. For example, he states that large extruded disc fragments are unlikely to resolve spontaneously and will usually require surgical treatment. This seems a logical proposition but my experience is that many of these large extrusions undergo complete clinical and radiological resolution within 2 or 3 months. Paradoxically, it is often the smaller contained disc prolapses which fail to improve with conservative measures. Like many orthopaedic surgeons he is persuaded by the alluring theories of discogenic low back pain and worships at the altar of segmental microinstability. However, I agree with much that he has written and differences of emphasis are inevitable in a field that is strong on dogma and short of established truths.

I would have no hesitation in recommending the text to trainees as the book is very readable and makes a good introduction to the management of lumbar disc disease. Nearly all aspects of diagnosis and treatment are covered but I was disappointed with the chapter discussing results of surgery. There is no mention of the use of objective validated disability and quality of life instruments in the assessment of outcome. For a text that aims to be comprehensive this constitutes a serious omission. It is because practitioners have failed to use objective outcome measures to establish the natural history of lumbar disc disease and the effects of therapeutic interventions that there remains so much uncertainty about management. These uncertainties cover (among others) physiotherapy, manipulation, timing of radiology, timing of surgery, whether spinal fusion is ever indicated, and what treatments are clinically and cost effective. Despite these drawbacks, surgeons who manage lumbar disc disorders will want to have a copy of this book, either on their own or their departmental library's shelf.

RODNEY LAING
Chronic Fatigue and its Syndromes. By SIMON WESSELY, MATTHEW HOTOPF, and Michael Sharpe. (Pp 428, £29.50). Published by Oxford University Press, Oxford, 1998. ISBN 0-19-263046-6.

My first sensation is that such a book is long overdue. There is a paucity of books written by clinicians on this subject compared with the many gloom and doom tracts written by sufferers who have apparently been ill with CFS/PVS/ME for 20 years and which depress the hell out of the patients that I see. Why this lack? Undoubtedly because relatively few doctors want to put their heads above the parapet and profess to a great expertise or desire to see patients with it. It is a condition for which there is no objective test, no objective monitoring of progress, whose symptoms are so vague that they repeatedly defy classification and can only be catalogued. Among those patients with a genuine postinfectious fatigue (who mainly get better relatively quickly) there is a large body of those with hospital records measured by the kilogram who arrive with sheaves of self compiled additional notes and occupy huge periods in the clinic to little effect other than frustration for both doctor and patient. Why they do this is a different story.

So what about the book? Firstly I must say it comes armour plated against criticism with a pack of glowing references from ennobled and famous physicians on the back. Presumably the authors chose these referees whose major feature in common is distinction in fields other than chronic fatigue syndrome. So, for whatever reason they were chosen the result is also to make this a poisoned chalice to review if one has the temerity to disagree with such a company.

Chronic fatigue and its Syndromes is written by three psychiatrists. That in itself is a little odd as although psychiatric illness is quite common in the chronic fatigue syndrome group, most patients with chronic fatigue syndrome are very reluctant to be seen on first presentation by psychiatrists. One usually has to reassure them that one is not dismissing their symptoms as psychiatric if one does suggest such a referral. What proportion of patients I wonder go to psychiatrists as their first hospital referral? I would guess very few.

The book is very comprehensive. As a source of references on the subject of fatigue it is encyclopaedic. It begins with a nice history of the syndrome. Of a 428 page book only 44 pages cover assessment of the patient and a very telling paltry 14 are devoted to treatment. What is all the rest? The answer is that the authors have attempted to deal with every fatigue associated subject including: aetiology of chronic fatigue syndrome (summary - not known) and in a move which Sir Humphrey Appleby might have described as "courageous" they have ventured way outside their own areas of expertise into subjects such as viruses and immunity. The result is a collection of comprehensively referenced and uncritically selected facts from the literature, many of which are very useful, such as the collected data on enteroviruses and chronic fatigue syndrome but much of which is of uncertain value-for example, "divorced and separated women have higher titres of EBV-VCA antibodies" quoted out of context but not unrepresentatively. To glean interesting and important information from this book requires a fair degree of skill in distinguishing timber from forest.

When in their own field of psychiatry there is, unsurprisingly, a much more confident and informative air to the book. It is 
disappointing and somewhat introspective that they did not think that subjects such as neurobiology, microbiology, and immunology might justify equally expert contributors.

Is it an easy read? There is no easy way to write on a subject such as this, bedevilled by lack of objective facts and the writers have chosen a discursive, debating style which when not tightly controlled can slip towards verbosity. This, however, is not a standard medical text book and it would be unfair to make direct comparisons.

Is this a useful book? As a source of references, yes. As a guide to clinicians I am less convinced. The two commonest questions patients ask are hardly mentioned: "How long does the illness last?" and "What are my chances of recovery" Cognitive behavioural therapy is concisely and usefully summarised. There is a single page on complementary treatment, which again is often an area of considerable interest to patients notwithstanding the lack of controlled evidence for or against it.

On that note it is perhaps appropriate to quote one very intelligent patient with chronic fatigue syndrome I saw who became ill during his $\mathrm{PhD}$. "I've done a lot of reading and internet searching about the causes and possible cures of this, before I came to see you" he said "It seems to me that most people have an illness a bit like that which you commonly see after glandular fever and nobody seems to think it odd that after glandular fever you can feel unwell for quite a long time" he continued "If most people get better from this" (and many do) and if you try all sorts of other treatments like homoeopathy, acupuncture, meditation then the one you were doing when you got better will be the one you think cured you". He had of course discovered the maxim of entertaining the patient while nature gets them better. One could do worse perhaps than keep patients with chronic fatigue syndrome occupied, if not necessarily always entertained for quite a while, by recommending this book for them to read. They might end up with a greater understanding of fatigue and they would certainly realise how little really is known and how the search for an instant cure (which drives many of them) is currently futile.

ANDREW LEVER

Migraine and Headache Pathophysiology. Edited by LARS EDVINSSON. (pp 184, £65.00). Published by Martin Dunitz Publishers, London, 1999. ISBN 1-85317-737-7.

New information about how and why migraine happens continues to break on us in a dizzying succession of waves coming from various journals in different disciplines. We need an accessible, understandable, and unitary vehicle to collect, organise, and present this information. Journals, the Internet, and the abstracting services have their place, but for this purpose nothing beats the book. How well does Lars Edvinsson's Migraine and Headache Pathophysiology meet this need?

This book has several attractive features. Recognising that some of the world's best science is now being done in the laboratories of industry, it has enlisted as authors several leading researchers from the major pharmaceutical manufacturing companies, in addition to "the usual suspects" from academe. Not only has this introduced some exciting writers to the "review book" audience, but it has provided a particular insight into the science of determining why drugs work, or don't work, in migraine. The book is up to date, containing many 1998 references. Another strong point of the book it its comprehensiveness; though only 184 pages long, it covers every major aspect of the pathophysiology of migraine. There are chapters on innervation of cranial blood vessels, receptor physiology, neurotransmitters, 5-hydroxytrptamine receptor subtypes, cortical spreading, depression, neurogenic inflammation, arteriovenous shunts, cerebral haemodynamics, and animal modelling. This is achieved at the expense of some pretty terse prose at times, which can make it difficult for the non-expert to follow. It should be noted that, the title notwithstanding, this book deals almost exclusively with the pathophysiology of migraine, and the reader who buys it to get some insight into the mechanisms of tensiontype headaches, or other kinds of headache, is going to be disappointed.

Who should read this book? Certainly the migraine research should. Though much of it will be familiar to those who have kept up with the literature, it is nevertheless an attractive and handy compendium of current research information. Moreover, the first chapter (by Lars Edvinsson) and the last chapter (by Peter Goadsby) are very pretty syntheses of the field. What about clinicians? Some of it is heavy going for people like me, who are not basic scientists. But I got through it all in about 6 hours, and found I knew more about migraine coming out than I did going in - which makes reading it a very worthwhile exercise.

JOHN EDMEADS

Systemic Diseases, Part II. By mu AmINofF and CG GOETZ. (Handbook of Clinical Neurology, series edited by PJ VINKEN and GW BRUYN. (Pp 486, US\$224.00). Published by Elsevier Science, Amsterdam, 1998. ISBN 044481289X.

There is something about the anachronistic binding of the Handbook of Clinical Neurology series that is rather reassuring. Surely if classic phenomenological neurology is to be found anywhere, it will be between these fake leather embossed covers. This volume, the second of three on the neurology of systemic diseases, does nor disappoint. Here, in 450 pages of close type and few illustrations, are covered the neurology of orthopaedic, endocrine, gastrointestinal, and metabolic disorders. Goetz and Aminoff, the volume editors, have assembled an authoritative panel of authors that equitably straddle the Atlantic. There are detailed reviews of familiar territory such as diabetes, orthopaedic trauma, thyroid diseases, and porphyria. Cole's historical survey of B12 deficiency is particularly fine. In addition there are excellent chapters on more arcane topicsfor instance the neurology of pancreatic transplantation and intestinal pseudo-obstruction. Perhaps the movement disorders associated with coeliac disease could have been mentioned and a chapter on the neurology of inflammatory bowel disorders is certainly lacking. But these are trifling complaints against a text that, with its twin volumes, is significantly more comprehensive than any other account of the neurology of systemic diseases. It is hard to imagine a practicing neurologist requiring (or easily affording) a personal copy of all three volumes, but the local medical library should certainly buy them; both neurologists and general physicians will work the better for having them close to hand.

ALASTAIR COLES
Advances and Technical Standards In Neurosurgery. Volume 24. Editor In Chief F CoHAdon. (Pp 57, US\$159.00). Published by Springer-Verlag, Wien, 1998. ISBN 3-211-83064-2.

Advances and Technical Standards in Neurosurgery is sponsored by the European Association of Neurosurgical Societies. The intention is to publish reviews of topics in which recent advances have been made, and to invite acknowledged experts to present in depth accounts of established knowledge in various fields of neurosurgery.

The advances under review in this volume are the contribution of the septal region to memory, the in vivo metabolic investigation of cerebral gliomas with PET, and the use of image guidance in neurosurgery. In the technical standards section, Professors Valavanis and Yasargil discuss the endovascular treatment of arteriovenous malformations, Dr Guglielmi reports on the interventional neuroradiological treatment of intracranial aneurysms, and Dr Sussman and colleagues describe the management of benign intracranial hypertension.

This book is aimed primarily at young neurosurgeons, but is an excellent source of reference for those who are already trained. The fact that it is in its 24 th volume is a testament to its success in achieving this objective.

ROBERT MACFARLANE

Hospitalist Neurology. Blue Books of Practical Neurology. Edited by MARTIN A SAmuels. (Pp 748, £70.00). Published by Butterworth Heinemann, Oxford, 1999. ISBN 0750697792.

It seems that there is a new specialty in North American neurology, hospitalist neurology. The drive to promote managed health care has apparently resulted in hospitals "filled to overflowing with more acutely ill patients requiring a pace of evaluation unprecedented anywhere in the world". Enter the hospitalist neurologist. Unencumbered by the demands of outpatient neurology, he or she stumbles through the wards of the general hospital "faced with a dizzying array of neurologic problems". Most British neurologists have a ward referral practice and will not be impressed by its elevation to the status of a specialty and still less by the agrammatical title Martin Samuels has chosen for it. Which is a shame, because this book deserves a wide readership. One in the Butterworth Heinmann series of Blue Books of Practical Neurology, it is attractively produced and reasonably well illustrated. Its place on your bookshelf is earned by collating the neurological aspects of diverse medical specialties: to name a few, organ transplantation, orthopaedics, oncology, and urology. A quick glance here before a ward referral might well be rewarding. However, the chapters on more conventional neurological topics, such as neuro-ophthalmology, stroke, and seizures are probably briefer than most neurologists would require. So, for those made dizzy by the delirious patient after bypass, the encephalopathic flapping on the transplant ward, or the weak and wasted on intensive care units, this is for you. And remember: you are a hospitalist neurologist.

ALASTAIR COLES 
Symptom Management in Multiple Sclerosis, 3rd Edition. By RANDALL T sChaPIRo. (Pp 176, US\$19.95). Published by Demos Medical Publishing, New York, 1998. ISBN 1-888799-22-6.

This is one of a new type of medical textbook written to meet the needs of an increasingly informed patient population. Aimed very much at those with multiple sclerosis, their families, and careworkers, it is simple and clearly written with jargon and technical terms kept to a minimum but without patronising. Chronic diseases, and especially multiple sclerosis, are not always well managed by the physician. Too many of us think that there is no cure and feel helpless in a busy clinic faced with the patient with a long list of complaints. There are too few specialty multiple sclerosis clinics in which neurologists, pain specialists, uroneurologists, physiotherapists etc liase.

Patients often feel left in the dark, unaware which of their symptoms can be attributed to their multiple sclerosis and whether it is "worth bothering a busy doctor". Many can cite bad experiences in their past when they have been fobbed off with well meaning reassurance but without practical help. Dysaesthesia, sexual problems, and urinary incontinence are only a few of the symptoms that can bring misery to the lives of patients and their families and which are poorly addressed by doctors. This book, in a language accessible to most (and with a glossary to explain some unavoidable jargon), explains multiple sclerosis, its symptoms, and what might realistically be obtained in terms of symptom control. All aspects are covered and nothing considered too trivial; constipation or cold feet might be extremely trying for an individual patient and each is considered.

The old idea that is doesn't help a patient to know too much about his disease ("it will only make him introspective and hypochondrial") is outdated. Multiple sclerosis can hit anyone and patients now want, and deserve, to be informed. While doctors find it challenging to be faced with a patient equipped with the latest information down loaded from the internet or well informed having read a book such as this, this is a challenge to which we must be ready to rise. This textbook provides the information patients want and fills the gap left by busy doctors. It should be marketed appropriately and we must be ready to respond to the reaction of patients. Perhaps someone with multiple sclerosis should have been invited to write this review.

GILLIAN HALL

\section{CORRECTION}

Goldenberg G, Schuri U, Grömminger O, During printing, the figure in this paper ( $p$ Arnold U. Basal forebrain amnesia: does the 164) was made darker than the original. The nucleus accumbens contribute to human correct version appears below. memory? F Neurol Neurosurg Psychiatry 1999; 67:163-8.

A

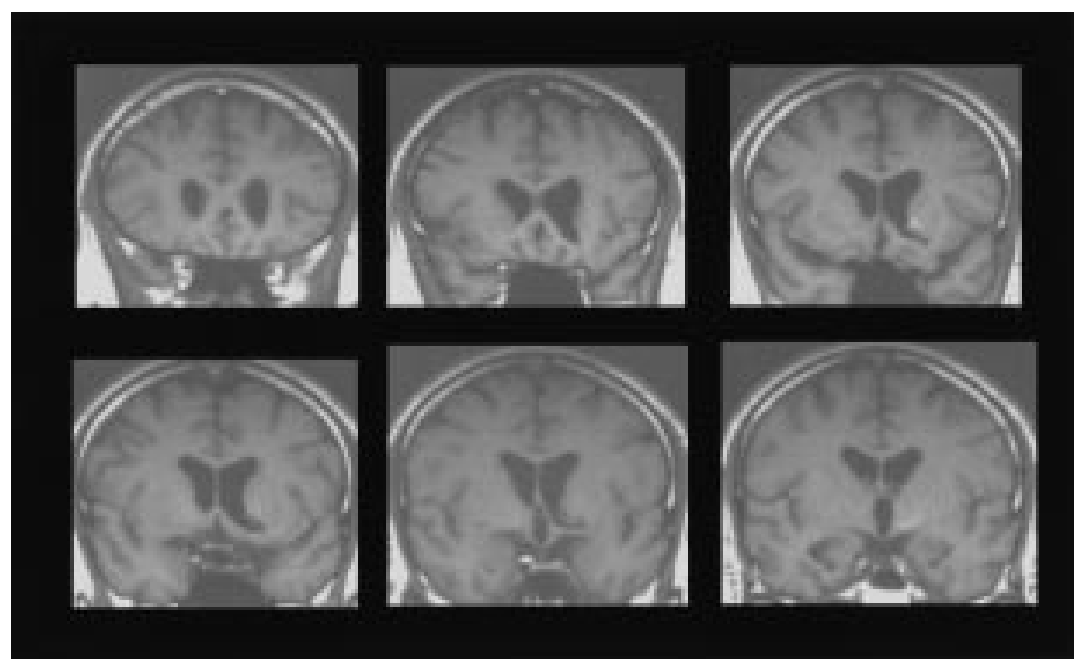

B

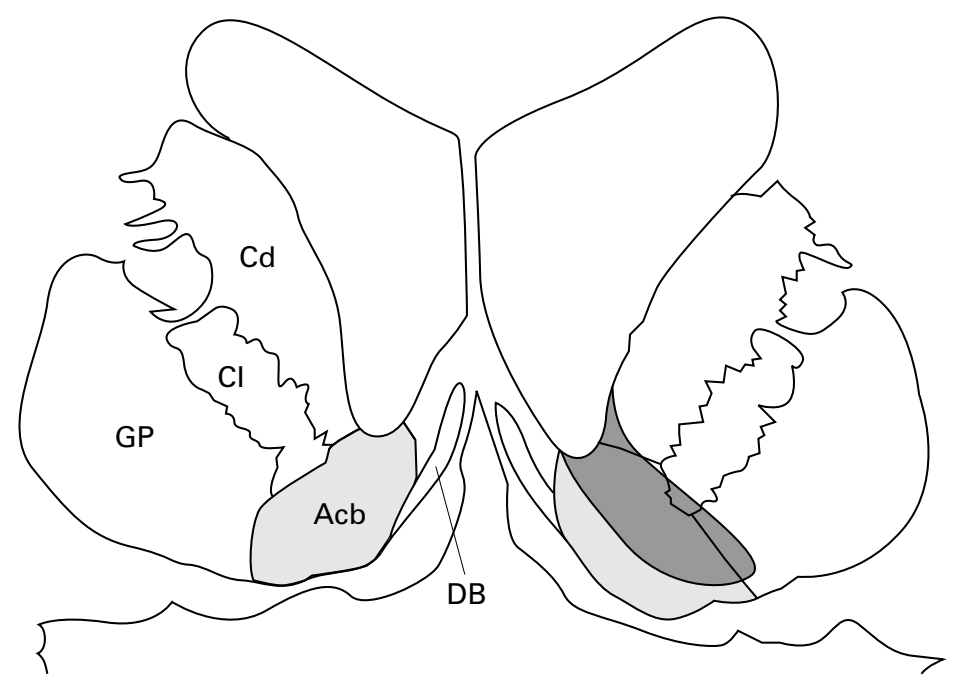

(A) T1 weighted MRI of the lesion. (B) Anatomical scheme of the centre of the lesion, corresponding to the leftmost image of the bottom row of the MRI. The right side of the figures corresponds to the left side of the brain. $G P=$ globus pallidus; $C d=$ caudate nucleus, $A c b=$ nucleus accumbens; $C I=$ capsula interna; $D B=$ diagonal band. 